\title{
Title: Population Screening for Inherited Predisposition to Breast and Ovarian
}

Cancer

Authors: Ranjit Manchanda ${ }^{1,2}$, Sari Lieberman ${ }^{3,4}$, Faiza Gaba ${ }^{1,2}$ Amnon Lahad ${ }^{4,5}$, Ephrat LevyLahad $^{3,4}$

1 Wolfson Institute of Preventive Medicine, Queen Mary University of London, Charterhouse Square, London EC1M 6BQ

2 Department of Gynaecological Oncology, Barts Health NHS Trust, London, UK

3 Medical Genetics Institute, Shaare Zedek Medical Center, Jerusalem, Israel.

4 Faculty of Medicine, The Hebrew University of Jerusalem, Jerusalem, Israel.

5 Clalit Health Services

Emails and ORCID numbers:

Ranjit Manchanda: Email: r.manchanda@qmul.ac.uk, ORCID number: 0000-0003-33815057

Sari Lieberman. Email: sari@szmc.org.il

Faiza Gaba: f.gaba@qmul.ac.uk

Amnon Lahad. Email: amnonl@ekmd.huji.ac.il

Ephrat Levy-Lahad. Email: lahad@szmc.org.il, ORCID number: 0000-0002-2637-1921

Running title: Population screening for BRCA

Keywords: BRCA1, BRCA2, Ashkenazi Jews, population screening, disease prevention, breast cancer

Corresponding author: Ephrat Levy-Lahad.

Medical Genetics Institute

Shaare Zedek Medical Center

POBox 3235, Jerusalem 91031, Israel.

Email: lahad@szmc.org.il. Tel: +972-26555384 Fax: +972-2-6666935 


\section{Abstract}

Discovery of genes underlying inherited predisposition to breast and ovarian cancer has revolutionized the ability to identify women at high risk for these diseases before they become affected. Such women can undertake surveillance and prevention measures shown to reduce morbidity and mortality. However, using current strategies, the vast majority of these women remain undetected until they become affected. In this review we show that universal testing, particularly of the BRCA1 and BRCA2 genes, fulfills classical disease screening criteria. This is particularly true for $B R C A 1 / B R C A 2$ in Ashkenazi Jews, but is translatable to all populations, and may include additional genes. Utilizing genetic information for large-scale Precision Prevention requires a paradigmatic shift in health care delivery. We propose a "Direct to Patient" model to address this need, which is increasingly pertinent in order to fulfill the promise of utilizing personal genomic information for disease prevention.

\section{Introduction}

Identification of the BRCA1 and BRCA2 genes in the mid-1990s ushered the era of genetic testing for inherited susceptibility to breast and ovarian cancer. In the 25 years following this landmark, BRCA1 and BRCA2 have been studied extensively. Risks associated with carrying deleterious variants in $B R C A 1 / B R C A 2$ have been delineated $(89 ; 119)$, and effective strategies for early detection and prevention have been shown to reduce morbidity and mortality in carriers $(42 ; 51 ; 73)$. An extensive spectrum of variants, $>5,000$ in each gene(95), has been revealed and assessed for pathogenicity. Biological functions of $B R C A 1$ and $B R C A 2$, which were unknown at the time of gene discovery, have been determined(183). This has led to development and application of targeted therapy for tumors caused by deleterious variants in these genes(102; 156). In parallel, additional breast/ovarian cancer predisposition genes have been recognized, and the advent of genomic sequencing technologies has revolutionized 
the testing landscape, enabling simultaneous analysis of multiple genes at greatly reduced cost.

These developments provide the underpinnings of a Precision Medicine approach to inherited breast and ovarian cancer predisposition. Precision Medicine has been defined as "an emerging approach for disease treatment and prevention that takes into account individual variability in genes, environment, and lifestyle for each person" $(4 ; 37)$. The germline genetic variability underlying cancer predisposition has so far been utilized primarily for cancer therapy, largely in patients with advanced malignancies(178). However its greatest potential is likely to lie in disease prevention, so-called "Precision Prevention"(68; 150; 151). As we have previously stated: "To identify a woman as a carrier only after she develops cancer is a failure of cancer prevention. (85).

Undertaking gene-based prevention at the population level, requires a population screening approach. The principles of population screening for disease were originally delineated in 1968 by Wilson and Jungner(191) (Table 1) and have informed various screening programs, e.g. newborn screening for metabolic and genetic diseases, preconception carrier screening and screening adults for hypertension and hypercholesterolemia(84). An underlying assumption of disease screening is that it is not intended to identify all individuals with the disease, rather to cast a wide net that will capture a significant proportion of at-risk individuals in a cost-effective manner. In this sense it is fundamentally different from using Precision Medicine tools to determine treatment options for a specific patient.

In this review, we assess current knowledge on genetic testing for breast cancer predisposition within the framework of population screening principles.

Review scope: We focus on population screening for BRCA1/BRCA2 in Ashkenazi Jews (AJs), since most of the current evidence base for such screening is based on testing founder 
BRCA1/BRCA2 deleterious variants (mutations) in this population. We also assess other populations and the question of widening the scope of screening to include additional breast/ovarian cancer predisposition genes.

The founder deleterious variants common in AJ are 185del AG and 5382insC in BRCA1 and 6174delT in BRCA2. Their combined frequency in unaffected $A J$ is 1:40 (2.5\%)(159). The formal nomenclature for these variants is NM_007294.3 (BRCA1):c.68_69delAG(p.Glu23Valfs), NM_007294.3(BRCA1): c.5266dupC (p.Gln1756Profs), and NM_000059.3(BRCA2): c.5946delT (p.Ser1982Argfs). We use the original names for these variants because they are commonly used in the literature and are more widely familiar. Deleterious variants in BRCA1, BRCA2 and other genes implicated in predisposition to breast and ovarian cancer also increase the risk for various other malignancies, in both women and men. For example, BRCA2 deleterious variants are also associated with increased risk for breast cancer and pancreatic cancer in both genders and for prostate cancer in men(8). In this review we focus on $B R C A 1 / B R C A 2$ population screening for prevention of breast and ovarian cancer in women. These malignancies account for the majority of BRCA1/BRCA2-related cancers and for most of the current data.

\section{A. Importance of breast and ovarian cancer in women, and the role of inherited predisposition in these malignancies (Table 1, principle 1)}

Breast cancer is the most common cancer in women globally, excluding non-melanoma skin cancer. Invasive breast cancer incidence is currently about 2.1 million women worldwide(2), including an estimated 268,600 women in the USA alone (1). In women, breast cancer is the leading cause of cancer deaths worldwide(2) and the second leading cause of cancer deaths (following lung cancer) in most developed countries(1). Breast cancer accounts for approximately $15 \%$ of cancer deaths, annually numbering 41,760 and 626,700 women in the 
USA and worldwide respectively $(1 ; 2)$. Ovarian cancer is about 10 -fold less common, but it is the most lethal gynecological malignancy. Ovarian cancer incidence is estimated at 295,414 women globally(26), including 22,530 women in the USA(1), but it accounts for $5 \%$ of all cancer deaths(1). In the USA, the 5 year survival rate for ovarian cancer is $47 \%$, compared to $90 \%$ for breast cancer (1).

Family history is a major risk factor for both breast and ovarian cancer, largely as a result of inherited predisposition(177). BRCA1 and BRCA2 remain the most commonly mutated genes underlying hereditary breast-ovarian cancer, with the highest cancer risks for carriers. However germline mutations in additional genes are known to increase risk for breast cancer or ovarian cancer. Deleterious variants in ATM, CDH1, CHEK2, NF1, PALB2, PTEN, TP53 and STK11 increase breast cancer risk(8; 96) and deleterious variants in the genes underlying Lynch syndrome: MLH1, MSH2, MSH6 and PMS2, as well as RAD51C and RAD51D increase ovarian cancer risk(8; 96). Other associations are remain controversial or uncertain. This includes the role of some breast cancer genes in ovarian cancer predisposition (e.g. ATM, PALB2), the role of some ovarian cancer genes in breast cancer (e.g. RAD51C, RAD51D, BRIP1), and the role of other candidate genes, e.g. BARD1 in breast cancer, or $(8 ; 96)$.

\section{Attributable risk of germline mutations}

The proportion of breast and ovarian cancer attributable to deleterious variants in $B R C A 1 / B R C A 2$ and the other predisposition genes varies between populations(16). Multiple studies on the genetic basis of these malignancies have been performed in cancer patients selected for family history, specific tumor pathology (e.g. triple negative breast cancer), young age at diagnosis, and other factors. In the context of population screening, it is important to determine the attributable risk of deleterious germline variants in the general population, i.e. in patients with minimal ascertainment bias. For BRCA1/BRCA2 in breast cancer, among $A J$, 
approximately $10 \%$ of unselected breast cancer patients are carriers of one of the three common deleterious variants(86) which account for $>90 \%$ of the BRCA1/BRCA2 mutational spectrum in AJ $(54 ; 163)$. In a large cohort of unselected AJ breast cancer patients who underwent sequential testing (founder variant testing followed by full sequencing) 104/1007 (10.3\%) carried a founder deleterious variant, and $7 / 1007$ (0.7\%) carried a non-founder $B R C A 1 / B R C A 2$ deleterious variant (186). In outbred, unselected women with breast cancer, recent studies using full gene sequencing find that the rate of $B R C A 1 / B R C A 2$ carriers is approximately $6 \%(92 ; 180)$, with similar results $(6.3 \%)$ in large cohort of $>18,000$ breast cancer patients who underwent clinical testing (92).

The frequency of deleterious variants in non-BRCA1/BRCA2 breast cancer predisposition genes is lower than that of BRCA1/BRCA2. Reports of multi gene panel test (MGPT) results often include variants in genes considered as unrelated to breast cancer (e.g. variants in colon cancer genes), or whose association with breast cancer is still uncertain (e.g. BRIP1, NBN variants excluding $675 \mathrm{del5})$. Thus, even the lower rates observed for non-BRCA1/BRCA2 genes likely over-estimate the attributable risk of these genes. In a study of unselected AJ breast cancer patients, the rate of non-BRCA1/BRCA2 deleterious variants was $3.4 \%$, largely explained by the founder CHEK2 S428F deleterious variant (186). In outbred unselected breast cancer patients, the rate of deleterious variants in non-BRCA1/BRCA2 breast cancer predisposition genes is similar, 3.9-4.6\% $(92 ; 179 ; 180)$.

The attributable risk of known cancer predisposition genes is higher for ovarian cancer than for breast cancer. This is particularly striking among AJ, where the three founder BRCA1/BRCA2 variants account for approximately $40 \%$ of all epithelial ovarian cancers (74; 132). In mixed populations, the prevalence of $B R C A 1 / B R C A 2$ mutations in large series of unselected ovarian cancer patients was found to be $13 \%-18 \%(12 ; 138 ; 142 ; 185 ; 194)$. The 
contribution of non-BRCA1/BRCA2 genes to ovarian cancer is also larger than their contribution to breast cancer. This is partly explained by the effect of Lynch syndrome, which though largely a colon cancer predisposition syndrome, is also associated with increased risk for ovarian cancer; along with some recently validated moderate risk ovarian cancer genes. Reported rates of non-BRCA1/BRCA2 deleterious variants in ovarian cancer are $5.7 \%-6.8 \%(92$; $137 ; 138)$.

\section{B. Carrier status for breast/ovarian cancer predisposition: A defined latent/presymptomatic} stage (Table 1, principles 4,8) .

Deleterious variants in $B R C A 1$ and $B R C A 2$, as well as in other cancer predisposition genes, clearly increase cancer risk in individual carriers (see Natural History, below). Thus, as long as a carrier of a deleterious variant is unaffected with a specific cancer, carrier status is essentially a pre-symptomatic stage for that particular malignancy. In the case of $B R C A 1 / B R C A 2$, an individual unaffected with any cancer is pre-symptomatic for any BRCA1/BRCA2-associated cancer, whereas a carrier affected with breast cancer can still be regarded as pre-symptomatic for other associated malignancies (e.g. ovarian or pancreatic cancer). The definition of the pre-symptomatic stage is thus clear-cut, so the question is essentially who should be tested to determine if they are carriers.

Currently, the majority of individuals who undergo germline cancer predisposition testing have a personal history of cancer $(39 ; 91)$. Multiple guidelines issued by various professional bodies largely focus on criteria for selecting affected individuals for testing based on the type of cancer, age at diagnosis, family history, tumor pathology, and in some cases AJ ethnicity Table 2. In affected women such testing is performed to inform treatment, but obviously, prevention can be achieved only by identifying high-risk carriers before they become affected. Current testing guidelines for unaffected individuals are shown in Table 2, which compiles ten 
different guidelines from the USA, Europe, and Australia, all published in recent years (20152019). Essentially all guidelines recommend genetic testing for unaffected women only if there is a known BRCA1/BRCA2 deleterious variant in their family (i.e. cascade testing), or if they have significant family history of $B R C A 1 / B R C A 2$-associated cancers. Comparing the same guidelines over time shows that the threshold for recommending testing has been lowered somewhat. However, except for the very recent version of the NCCN guidelines(2020 v.1)(8), the threshold for genetic testing is a family history that corresponds to a $10 \%$ probability of identifying a germline deleterious variant in BRCA1/BRCA2 (Table 2, (139)). With respect to unaffected AJ, some of the guidelines(8; 9) (139) (94),(19) regard AJ ancestry as one of the risk factors moving the needle towards testing, but generally in the context of family history. Among the six risk-assessment tools recommended by the USPSTF only half (3/6) include AJ ancestry as a risk factor, and the USPSTF explicitly recommends against testing unaffected women without family history (139). The most substantial change in testing recommendations for unaffected women is found in the most recent NCCN guideline, which states that genetic testing can be considered in unaffected women either if they are of AJ ancestry, or if accepted risk assessment tools indicate a $2.5-5 \%$ probability of identifying a BRCA1/BRCA2 deleterious variant(8). The $2.5 \%$ threshold is consistent with the carrier rate in

\section{AJ.}

Family-history based criteria remain central even in updated recommendations, and even they have been shown repeatedly to miss approximately half of $B R C A 1 / B R C A 2$ carriers. Among $\mathrm{AJ}$ in Israel, a population based study of BRCA1/BRCA2 families identified through unaffected males found that $51 \%$ had little or no relevant family history(57). In AJ screening trials in the UK(109; 114$)$ and in Canada(128) $60 \%$ and $55 \%$ of carriers respectively did not fulfill family-history based criteria. Lack of cancer history in families segregating $B R C A 1 / B R C A 2$ 
deleterious variants does not reflect lower risks $(57 ; 86)$, but is rather explained by limited family structure or knowledge of family history(188), multiple males and the chance occurrence of fewer older females who inherited the familial variant (57). These findings are consistent with observations from multiple case-series of unselected cancer patients, showing that $\sim 50 \%(20 ; 74 ; 75 ; 86)$ and up to $77 \%(131)$ of carriers detected following a cancer diagnosis lack suggestive family history.

Beyond the high prior probability thresholds required for testing unaffected women, existing guidelines present further barriers to testing. Family history criteria are often complex (Table 2), or involve use of risk assessment tools that are not familiar to most clinicians, particularly primary care physicians who have a critical role in referral $(9 ; 139)$. Additionally, although the NCCN has now added the option of pre-test education for individuals with a modest pre-test probability of $2.5-5 \%$, including AJ, all the guidelines surveyed recommend in-person genetic counseling $(\mathrm{GC})$ both pre-testing and post-testing. This is difficult to provide at scale, and may not be necessary (See Acceptability, below).

We note that current policies for BRCA1/BRCA2 testing contrast with the widely accepted policy of the American College of Medical Genetics and Genomics (ACMGG), which recommends return of information on deleterious $B R C A 1 / B R C A 2$ variants if these are found as incidental/secondary findings in the course of unrelated genomic tests (e.g. exome sequencing)(67; 79). Deleterious variants in BRCA1/BRCA2 and other high-penetrance cancer predisposition genes are reported back to patients irrespective of family history, and without in-depth specific pre-test information, because they are deemed to be medically important. In a study of $>50,000$ exomed individuals in the Geisinger Health System biobank (mean age 59.9 years), $0.5 \%$ of participants harbored a BRCA1/BRCA2 mutation(118). The investigators found not only that $49.4 \%$ of carriers did not meet family history criteria, but also that $82 \%$ of 
carriers (including many who met clinical criteria) had never been tested. Real-life data thus indicate that current strategies and barriers result in significant under-ascertainment, identifying only $\sim 20 \%$ of carriers(168). Critically, improved identification of carriers led to early diagnosis of cancer in these high-risk individuals(30). These data on considerable underascertainment of carriers are corroborated by a UK study, which showed that $90 \%$ of Jewish BRCA carriers and $97 \%$ of general population BRCA carriers across a 16 million London population remain unidentified despite $>20$ years of genetic testing in a centralized health system with free access to care(107). Additionally current rates of testing were inadequate to identify the residual pool of high risk $B R C A$ carriers who remained. These findings highlight the need for change and a new paradigm/approach to maximize precision prevention. Regarding non-BRCA1/BRCA2 genes, existing guidelines either discuss testing for rare cancer syndrome, e.g. LFS, but with the surge in use of MGPT, the criteria detailed in Table 2 are often used as the threshold for MGPT, since currently BRCA1/BRCA2 sequencing is largely performed as part of MGPT.

\section{The natural history of carrier status for cancer predisposition - cancer risks in carriers.} (Table 1, principle 7).

The natural history of carrier status for cancer predisposition is essentially the risk, by age, that a carrier will develop cancer, assuming there is no utilization of any special surveillance or prevention measures. In genetic terms this is the penetrance of deleterious variants in cancer predisposition genes. Penetrance can vary not only between different genes, but also between specific variants in the same gene(89; 155). For $B R C A 1$ and $B R C A 2$, cancer risks have also been shown to be affected by genetic modifiers $(90 ; 119)$ and non-genetic factors (e.g. reproductive history(55), calendar year at diagnosis(57; 86)). Penetrance of cancer predisposition genes has generally been evaluated through ascertainment based on affected 
individuals or those with significant family history. Such strategies exclude Individuals and families that harbor deleterious variants but did not develop cancers, and may overestimate penetrance in the population. This is likely to be particularly true for moderate or lowpenetrance genes, where risk may be more susceptible to other genetic or non-genetic effects.

Penetrance of the BRCA1/BRCA2 AJ founder variants. Population-based penetrance of the AJ founder BRCA1/BRCA2 variants was addressed by Gabai-Kapara et al (57). In this study, AJ women carriers were identified through healthy AJ males, which were representative of the general AJ population in terms of both carrier frequency and expected family history. The risk for breast cancer In BRCA1 founder carriers was $52 \%$ (SE 8\%) by age 70 years and 60\% (SE 10 \%) by age 80 years, and for BRCA2 6174delT carriers it was 32\% (SE 9\%) by age 70 years and $40 \%$ (SE\% 11\%) by age 80 years. The risk for ovarian cancer in BRCA1 founder carriers was $47 \%$ (SE 10\%) by age 70 years and 53\% (SE 11\%) by age 80 years, and the risk for BRCA2 6174delT carriers was $13 \%$ (SE 7\%) by age 70 years and 62\% (SE $18 \%$ ) by age 80 years.

These risks are comparable to those found in a recent large prospective cohort study of carriers from multiple ethnic origins that included a separate analysis of the AJ founder variants (89). This study had mixed ascertainment of affected and unaffected carriers through cancer genetic clinics. Breast cancer risk for carriers of the BRCA1 founder variants by age 70 was $84 \%$ (95Cl 68\%-94\%) for 185 delAG carriers and $60 \%$ (95Cl $45 \%-75 \%$ ) for 5382 ins C carriers (carriers of this variant are not necessarily AJ since $5382 \mathrm{ins} \mathrm{C}$ is a common BRCA1 deleterious variant in Central/Eastern Europe and not unique to $\mathrm{AJ}(63 ; 181))$. Breast cancer risk for BRCA2 6174 delT carriers was $41 \%(95 \mathrm{Cl} 20-70 \%)$ by age 70 years. Ovarian cancer risks for BRCA1 carriers by age 70 were $35 \%$ ( $95 \mathrm{Cl} 20-36 \%)$ for 185 delAG carriers and $34 \%(95 \mathrm{Cl} 13-73 \%)$ for 
5382insC carriers. Ovarian cancer risk in BRCA2 6174delT carriers could not be assessed because of lack of events.

Thus, with respect to breast and ovarian cancer risks in the AJ, it is clear that cancer risks are high even in women carriers ascertained at the population level, and similar to those found through cancer genetics clinics: the combined population-based breast/ovarian cancer risk by age 80 years was $83 \%$ (SE 7 \%) for BRCA1 founder carriers and 76\% (SE 13\%) for BRCA2 6174delT carriers(57).

Penetrance of BRCA1/BRCA2 mutations in other populations. Over the years, multiple studies have addressed the penetrance of $B R C A 1$ and $B R C A 2$, progressing from estimates based on high-risk families, to case-series of cancer patients and to cancer genetics clinics, serving and ever-larger and less selected population (for a meta-analysis of earlier studies see(34)) . Two large recent prospective cohort studies from cancer genetics services $(89 ; 119)$ found that by age 70 years, breast cancer was $60-66 \%$ in BRCA1 carriers and $55-61 \%$ in BRCA2 carriers. Ovarian cancer risk by age 70 years was $41 \%-58 \%$ in $B R C A 1$ carriers and $15 \%-16.5 \%$ in $B R C A 2$ carriers. Cancer risks continued to rise from age 70 to 80 years.

The most notable difference between the risks found in a mixed population and those in $\mathrm{AJ}$ is the higher ovarian cancer risk for BRCA2 in AJ. This is explained by the fact that the data on founder AJ BRCA2 testing reflects the risks associated with the 6174delT variant, which is located in the BRCA2 Ovarian Cancer Cluster Region (59; 89; 155).

From a population screening perspective, experience from the AJ studies suggests that cancer risks for $B R C A 1 / B R C A 2$ carriers in the general non-AJ population level will be of similar magnitude to those observed in large, clinic-based studies. This reflects the high penetrance of $B R C A 1$ and $B R C A 2$ deleterious variants. 
Cancer risks in non-BRCA1/BRCA2 genes Data on cancer risks associated with deleterious variants in non-BRCA1/BRCA2 genes is much more limited, particularly data on populationbased risks. Many of the non-BRCA1/BRCA2 genes were identified in parallel with the development and increased use of MGPT. Consequently, penetrance estimates are often based on a case vs. database control approach, where the cases are clinically tested affected individuals compared to variant frequencies in public databases (e.g. ExAC). Even so, most of the non-BRCA1/BRCA2 genes are moderate risk genes, defined as those associated with an Odds Ratio (OR) of 2-4 fold for breast and ovarian cancer(45). For some genes commonly included in gene panels (e.g. MRE11A, SLX4) it remains unclear whether an association with breast/ovarian cancer exists $(8 ; 96)$. For the purposes of this review, we briefly discuss cancer risks of non-BRCA1/BRCA2 genes for which there is a consensus on their association with breast cancer (ATM, CDH1, CHEK2, NF1, PALB2, PTEN, TP53 and STK11) or ovarian cancer: (Lynch syndrome (MLH1, MSH2, MSH6 and PMS2), RAD51C and RAD51D)(8; 96). Genes are TP53, PTEN, CDH1, and STK11 deleterious variants are all highly penetrant breast cancer genes (i.e. associated with an $O R>4)(45)$. Prior to the genomic era, deleterious variants in these genes were identified based on specific cancer syndrome phenotypes. Li Fraumeni syndrome (LFS), caused by TP53 deleterious variants, includes increased significantly increased risk for a wide range of malignancies, in particular premenopausal breast cancer, soft tissue sarcoma, osteosarcoma, adrenocortical tumors, and brain tumors(10). Breast cancer risks in LFS families have been estimated at $54 \%$ by age $70(105)$. In a MGPT study of BRCA1/BRCA2-negative patients with both personal and family history of breast cancer The OR estimate for breast cancer in TP53 carriers was 11 (95Cl 0.61-201), but this was not statistically significant. This demonstrates the difficulty in achieving statistical power in assessment of rare variants: even in a study of 2000 breast cancer patients, the total number 
of TP53 deleterious was insufficient (5/2000 (0.25\%)). In two large MGPT studies (> 15,000 breast cancer cases) of individuals clinically tested in a commercial laboratory the ORs for breast cancer in TP53 carriers were 5.37 (95Cl $2.78-10.4)(91)$, and 2.58 (95Cl 1.39-4.9)(39). These results are driven by TP53 carrier rates of $0.013 \%(25 / 19,056$ and $48 / 38305$ respectively) among breast cancer patients(39; 91). Cowden/PTEN hamartoma syndrome (PTHS), caused by PTEN deleterious variants, is a multi-system disorder including non-cancer manifestations (e.g. macrocephaly, neurodevelopmental disease), as well as predisposition to malignancies other than breast cancer, e.g. thyroid and endometrial cancer (ref Genereviews). Breast cancer risk has been estimated as $77-85 \%(28 ; 175)$. In the large commercial laboratory-based MGPT studies the OR for breast cancer in PTEN carriers was $5.83(95 \mathrm{Cl} 2.43-14.0)(91)$ and $12.7(95 \mathrm{Cl} 2.0-258.9)(39)$. The frequency of PTEN carriers among breast cancer patients was $0.08 \%(15 / 19,056)(91)$ and $.052 \%(20 / 38,179)(39 ; 91)$. $\mathrm{CDH} 1$ underlies Hereditary diffuse gastric cancer syndrome which includes high risk for the lobular subtype of breast cancer (5). Penetrance for breast cancer in $\mathrm{CDH} 1$ has been estimated at $42.9 \%-52 \%(83 ; 192)$. In MGPT studies based on clinical testing in commercial laboratories the OR for $\mathrm{CDH} 1$ carriers was 5.34 (95Cl 1.6-10.9) in the larger study (39), but not significantly associated with breast cancer in general in the second study(91). STK11 deleterious variants cause Peutz-Jeghter syndrome (PJS), which is characterized by mucocutaeous pigmentation, gastrointestinal polyps, and increased risk mainly for colon cancer, but also for breast cancer and non-epithelial ovarian cancer(6). In STK11 breast cancer risks have been estimated as $32-54 \%$ and ovarian cancer risk (largely non-epithelial as $21 \%$. In large MGPT studies STK11 variants were significantly associated only with ovarian cancer, reflecting the rarity of STK11 deleterious variants.(91). 
Using the threshold of an OR of 4 , the remaining non-BRCA1/BRCA2 genes listed above are by and large moderate risk genes for breast and ovarian cancer in general. Possible exceptions are $R A D 51 C$ and $R A D 51 D$ which based on consistent observations may be regarded as high penetrance genes for ovarian cancer, with ORs of 4.98-5.1 for RAD51C and 4.78-6.3 for $\operatorname{RAD51D}(91 ; 100)$

\section{Accepted treatment surveillance and prevention measures in BRCA1/BRCA2 carriers.}

(Table 1, principles 2,3)

\section{Breast Cancer Surveillance}

Most international guidelines recommend that BRCA1/BRCA2 carriers are offered annual MRI and/or mammograms for breast cancer surveillance from the ages of $25-30$ years. $(52 ; 136)$ Commonly alternate breast imaging (mammogrphay and MRI) is performed every 6 months (8) In general, MRI has higher sensitivity but lower specificity than mammograms. This results in in higher need for breast biopsies, false-positive rates, recall, and need for additional imaging(135) However it is more useful in younger women with denser breast tissue, which is particularly relevant to carriers. A recent systematic review by the United States Preventive Services Task Force (USPSTF) reported sensitivity to be $63 \%$ to $69 \%$ for MRI, $25 \%$ to $62 \%$ for mammography, and $66 \%$ to $70 \%$ for combined modalities. The specificity was $91 \%$ or more for either modality alone or combined.(135) This review also did not find evidence for an effect of intensive surveillance on mortality .(135),

\section{Breast Cancer Prevention}

Risk reducing mastectomy (RRM) reduces the risk of breast cancer by $90-95 \% .(152)$. In a recent cohort study, RRM was found to reduce both breast cancer-specific mortality (HR=0.06 $(95 \% \mathrm{Cl} 0.01-0.46)$ and overall mortality $(\mathrm{HR}=0.40(95 \% \mathrm{Cl} 0.20-0.90))$ in $B R C A 1$ carriers. There was no effect on mortality in BRCA2 carriers, who had lower breast-cancer mortality than 
BRCA1 carriers(73). The overall complication rates of mastectomy are not insignificant, with rates of around $32-50 \%$ reported, although majority are minor complications.(41; 135) RRM rates may vary across countries with rates up to $\sim 50 \%$ reported.(124; 125$)$ Although RRM is linked with a negative impact on body-image and sexual pleasure, there are studies which also report no detrimental impact on sexual-activity, habit, discomfort,(25) anxiety, depression or quality-of-life. $(25 ; 77 ; 133)$ and high cosmetic satisfaction rates. $(77 ; 187) \mathrm{A}$ recent systematic review found that although body image and psychological symptoms may worsen in some women after surgery, most measures returned to baseline at a later date.(135) RRM has been shown to be cost-effective for prevention of breast cancer in BRCA1/BRCA2 carriers.(65)

A number of chemoprevention trials have evaluated Tamoxifen, Raloxifene, and the aromatase inhibitors Anastrozole and Exemestane for prevention of breast cancer in high risk women. These studies involved high risk women including $B R C A 1 / B R C A 2$ carriers but none were specific to $B R C A 1 / B R C A 2$ carriers. A USPSTF review shows that Tamoxifen $(R R=0.69$ [95\% Cl, 0.59-0.84]), Raloxifene ( $R R=0.44[95 \% \mathrm{Cl}, 0.24-0.80])$, and aromatase inhibitors ( $R R=$ $0.45[95 \% \mathrm{Cl}, 0.26-0.70])$ are associated with lower risk of invasive breast cancer after 3 to 5 years of use compared with placebo.(134) Tamoxifen (RR, 1.93 [95\% Cl, 1.33-2.68]) and Raloxifene (RR, $1.56[95 \% \mathrm{Cl}, 1.11-2.60])$ are associated with increased risk of thromboembolism, Tamoxifen with an increased risk of endometrial cancer (RR, $2.25[95 \% \mathrm{Cl}$ : 1.17-4.41]), while aromatase inhibitors have a negative impact on bone and musculoskeletal health.(40; 134) In a direct comparison study Tamoxifen was found to be better than Raloxifene in preventing invasive breast cancer though Raloxifene had a better toxicity or side-effect profile.(184) This reduction in cancer risk is found predominantly for estrogen receptor positive $(E R+)$ but not estrogen receptor negative (ER-) breast cancer or DCIS. 
However, as yet there is no explicit evidence for efficacy of chemoprevention specifically in BRCA1/BRCA2 carriers(8). Additionally, a mortality impact has not yet been demonstrated with chemoprevention.

\section{Ovarian Cancer Surveillance:}

Ovarian cancer surveillance in high risk BRCA carriers has been evaluated in a few international single arm studies utilizing CA-125 biomarker testing and imaging by pelvic ultrasound. These non-randomized studies were not designed to evaluate an impact on mortality/survival. Annual surveillance using absolute CA-125 and ultrasound scan is not effective and not advocated. The Phase-1 of UKFOCSS (United-Kingdom Familial-OvarianCancer-Screening-Study) reported a sensitivity of $81.3 \%-87.5 \%$, positive predictive value (PPV) of $25.5 \%$ and negative predictive value (NPV) of $99.9 \%$ with annual screening.(161) Only $31 \%$ of the cancers were early stage. Screening for ovarian cancer using a mathematical longitudinal biomarker based algorithms has been shown to be better than using absolute biomarker cut-offs. It can double the number of ovarian cancers detected compared to an absolute cut-off/threshold rule.(123) A strategy of more frequent (3-4 monthly) surveillance using the longitudinal CA125 based Risk of Ovarian Cancer Algorithm (ROCA) has been evaluated in high-risk women over 35 years in the UKFOCSS Phase-2 (4,348 women; 13,728 women screen years)(162) and the US Cancer Genetics Network (CGN) and Gynecological Oncology Group (GOG) trials (3692 women, 13,080 women-screen-years).(69; 171) The UKFOCSS Phase-2 study demonstrated a statistically significant stage shift with ROCA-based screening.(162) 7/19 (36.8\%) ovarian cancers were stage IIIb/IV if diagnosed within one year of last screen, whereas $17 / 18$ (94.4\%) ovarian cancers were stage IIIb/IV if diagnosed after one year following the last screen $(p=0.001)$. R0 resection (zero residual disease) at debulking surgery for ovarian cancer is an accepted surrogate for better survival. $95 \%$ of screen- 
detected cancers achieved this metric which is far higher than other reports in the literature in patients presenting with symptomatic disease. The study showed high sensitivity (94.7\%), positive predictive value (PPV) (10.8\%) and negative predictive value (NPV) (100\%) within one year of screening. More recently other longitudinal biomarker algorithms of promise have been developed and evaluated such as the Parametric Empirical Bayes (PEB)(44) and Method of Mean Trends (MMT) algorithms.(24) Overall surveillance data for 4-monthly/frequent longitudinal CA-125 algorithm based screening in high-risk women who decline risk-reducing surgery appear promising. However lessons learned from ovarian cancer surveillance studies show that for this to be effective/successful it is essential for gynaecologists or clinicians and cancer teams to change their mind-set and be being willing to undertake surgery (bilateral salpingo-oophorectomy) on the basis of a rising biomarker itself without any radiological corroboration of an abnormality. Currently there is no national ovarian cancer screening/surveillance programme in any country. A project evaluating 4-monthly ROCAbased surveillance in high-risk women, called Avoiding Late Diagnosis of Ovarian cancer (ALDO) is currently ongoing in the UK.

\section{Ovarian Cancer Prevention:}

Risk reducing salpingo-oohorectomy (RRSO) is the most effective way of preventing ovarian cancer in BRCA carriers. This is undertaken usually through laparoscopic surgery. It involves removal of both tubes and ovaries along with peritoneal cytology. A serial sectioning 'SEEFIM' protocol is used for pathological examination(122) and approximately 5\% women are detected to have an occult in-situ serous tubular in-situ carcinoma (STIC) lesion or microscopic invasive cancer $(106 ; 147)$ which is not identifiable via CA125 testing or imaging. $70 \%$ of which these lesions are tubal rather than ovarian(147) and a large proportion would be missed without a 'SEE-FIM' protocol. 
Studies show that RRSO is associated with a reduction in ovarian cancer risk ranging from 80$96 \%$ in BRCA1/BRCA2-carriers. $(49 ; 80 ; 81 ; 154)$ One meta-analysis found a $79 \%$ overall reduction in ovarian cancer risk ( $\mathrm{HR}=0.21, \mathrm{Cl}: 0.12,0.39)$ with $\mathrm{RRSO} .(153)$ There is a small 2$4 \%$ residual risk of primary-peritoneal cancer which remains (33; 50). Additional data also report a $79 \%$ reduction in ovarian cancer specific mortality, $56 \%$ reduction in breast cancer specific mortality and $60 \%$ reduction in all-cause mortality.(43) While earlier studies reported a reduction in breast cancer incidence, more recent literature controlling for biases showed no such reduction.(72) RRSO is a cost-effective intervention to prevent ovarian cancer. Costeffectiveness has been demonstrated in BRCA1/BRCA2 women with high ovarian cancer risk(13) as well as lower risk levels, with cost-effectiveness reported for women whose lifetime ovarian cancer risk is over 4-5\%.(111; 113)

RRSO is typically offered from ages $35-40$ years for BRCA1 carriers and $40-45$ years for BRCA2 carriers. Decision making may be affected by numerous factors, is a dynamic process and the timing needs to be individualized following informed counselling. RRSO has a complication rate of $3-5 \%$. A wide range of uptake rates of up to around $70 \%$ are reported in the literature. $(58 ; 108 ; 124)$ RRSO is associated with high satisfaction rates of up to $97 \%$ along with some regret, at rates of $\sim 5 \% .(103)$

RRSO in premenopausal women leads to premature menopause which has been associated with increased risks of heart-disease, stroke, osteoporosis, vasomotor symptoms, mood changes, sleep disturbance, reduced libido, vaginal dryness, sexual-dysfunction and neurocognitive decline predominantly in women who are unable to use hormone replacement therapy $(\mathrm{HRT}) .(47 ; 141 ; 160 ; 170)$ However, vasomotor symptoms and sexual- 
dysfunction are not fully alleviated by HRT, with symptom levels remaining above those who retain their ovaries.(103; 104) As a result some women delay oophorectomy till after menopause, which may be detrimental, particularly in BRCA1 carriers. HRT until age 50 years in carriers who have undergone RRSO has not been associated with increased breast cancer risk in carriers, and can be offered $(15 ; 62)$. While early salpingectomy and delayed oophorectomy has been proposed as an attractive alternative this remains well within the research arena.(56)

Surveillance and Prevention in non-BRCA1/BRCA2 carriers. Direct evidence on surveillance and prevention measure in carriers of genes other than BRCA1 and BRCA2 is limited. In general, the same modalities used in BRCA1/BRCA2 carriers are also utilized in carriers of other breast/ovarian cancer predisposition genes. This poses significant questions, particularly with regard to risk-reduction surgeries which may not be warranted for a number of the moderate or low penetrance genes. However, exception may exist with regards to RRSO for moderate to higher ovarian cancer genes (e.g. RAD51D, RAD51C and BRIP1) because there are no clearly effective means for early cancer detection. Another exception is Lynch syndrome. Although some Lynch syndrome genes are associated with only moderate ovarian cancer risks, Lynch syndrome carriers often undergo hysterectomy for prevention of endometrial cancer and RRSO is often performed in the same procedure. There is limited information to make clear recommendations regarding the ages from when surgical prevention/RRSO should be offered for some of the moderate risk carriers. Clinically, carriers of non-BRCA1/BRCA2 predisposition genes are often managed based on family history(8).

\section{E. Laboratory test suitable for population screening (Table 1, principle 5)}

The analytic validity of genetic testing for specific mutations and for MGPT is very high (>95\%)(46; 101; 169). In the population screening context, the main concerns regarding the 
choice of an appropriate test for variant detection are the test's sensitivity and specificity and its positive and negative predictive value. The predictive values also depend on the background frequency of deleterious variants. A further consideration is whether or not to report variants of unknown significance (VUS) in the screening setting.

BRCA1/BRCA2 laboratory testing in AJ. Options for testing BRCA1/BRCA2 in AJ include testing for the three founder deleterious variants or full gene sequencing. The advantages of founder testing include significantly lower cost, and the lack of VUS. Based on data from sequential AJ breast cancer patients tested first by founder variant testing (86), and subsequently using full gene sequencing (186), the sensitivity for the three founder deleterious BRCA1/BRCA2 variants is $94 \%(104 / 111)$. This figure is consistent with other data on frequency of nonfounder BRCA1/BRCA2 deleterious variants in AJ $(54 ; 163)$. The sensitivity of full $B R C A 1 / B R C A 2$ sequencing would in principle be almost complete, but certain classes of variants, such as rearrangements, are difficult to detect and human errors occur. False identification of individuals as $B R C A 1 / B R C A 2$ carriers is extremely low, so the specificity of both founder variant testing and full sequencing of BRCA1/BRCA2 is likely close to $100 \%$, largely related to human (e.g. sampling) error. The prevalence of founder deleterious variants is $1: 40$, and the prevalence of non-founder BRCA1/BRCA2 deleterious variants in the $A J$ population would be expected to be similar to the mean range in other populations, i.e. 1:300. Assuming $99.9 \%$ specificity, the positive predictive value (PPV) of testing for the founder variants is $96 \%$, and the negative predictive value is $99.8 \%$ (NPV). For full gene sequencing, assuming $99 \%$ sensitivity and $99.9 \%$ specificity, the PPV is $96.7 \%$ and the NPV is $100 \%$. Founder variant testing in AJ thus achieves predictive values that are only negligibly smaller than full BRCA1/BRCA2 sequencing ( $<1 \%$ difference), at a much lower cost and precluding the need to confront the issue of VUS. 
We are aware that these calculations do not address the predictive value for cancer diagnosis. Even in AJ, as detailed above, the majority of ovarian cancer cases and the large majority of breast cancer cases are not caused by germline BRCA1/BRCA2 deleterious variants. However, this will be true of any individual Precision Prevention application, and the ultimate utility of the population genetic screening approach can be evaluated by cost-effectiveness analyses. BRCA1/BRCA2 laboratory testing in non-AJ. There are ethnic groups other than AJ with founder deleterious variants in BRCA1/BRCA2. However, in the majority of populations identifying any significant fraction of $B R C A 1 / B R C A 2$ deleterious variants requires full sequencing of $B R C A 1$ and $B R C A 2$. The sensitivity and specificity of $B R C A 1 / B R C A 2$ full sequencing is the same as in AJ. The positive and negative predictive values of such an endeavor hinge on the background frequency of deleterious variants. Historically, epidemiological estimates suggested a 1:150 carrier frequency for a major dominant breast cancer predisposition gene (allele frequency was estimated as .0033)(35). This estimate includes all dominant breast cancer predisposition, i.e. not only BRCA1 and BRCA2 deleterious variants. In 1997 Australian women cancer-free controls, combined carrier frequency of BRCA1 and BRCA2 (based on full sequencing as part of a MGPT) was 1:153. These women were ascertained through a population-based mammography screening program and their mean age was 59.9 years. Since many carriers will have become affected by age 60 years, this prevalence would be expected to be lower than the population prevalence at age 30 years. In the Geisinger Health Care biobank, among 50,276 who underwent exome sequencing, the prevalence of $B R C A 1 / B R C A 2$ deleterious variants was $0.5 \%(1: 180)(118)$. Compared with the health system's overall population biobank participants were older (mean age 59.9 vs 50.1 years) and enriched for relevant cancers, although overall there was a low proportion of participants with a previous breast/ovarian cancer diagnosis $(1.7 \%$ in the biobank vs $0.1 \%$ in 
the entire system). Excluding participants with a previous breast or ovarian cancer diagnosis, carrier rate among women in this biobank was $0.36 \%$ (1:277). Similarly to Australian controls, the older age of this study group would suggest this figure is underestimate of carrier prevalence at younger ages. An analysis of publicly available variant data from large databases (the Exome Variant Server (EVS)(7) and the Exome Aggregation Consortium (ExAC) database(3)) excluding The Cancer Genome Atlas (TCGA) samples found a combined $B R C A 1 / B R C A 2$ carrier rate of 1:166 in EVS and 1:161 in ExAC(120). Notably, carrier rates varied widely in different ethnic groups, ranging from 1:123 in ExAC Europe and to 1:626 in Africans (120). Assuming 99\% sensitivity and $99.9 \%$ specificity, for background carrier rates of 1:160 or $1: 300$ the PPV is $86.2 \%$ and $76.8 \%$ respectively, and the NPV in both cases is $100 \%$. These PPVs are significantly higher than those of many accepted disease screening strategies. Laboratory testing for non-BRCA1/BRCA2 genes. Assuming only "actionable" genes clearly associated with high penetrance are considered as candidates for large scale screening MGPTrelated issues are similar in AJ and non-AJ. The main issues are the PPV and NPV, VUS (see below), and cost (see below). As noted above, predictive values are contingent upon population frequencies. For example, the frequency of RAD51C in unaffected individuals tested through MGPT was 72/52,100 (likely an overestimate since clinically unaffected individuals are enriched for family history)(91). Assuming $99 \%$ sensitivity and $99.9 \%$ specificity of testing the PPV is $58.2 \%$ and the NPV is $100 \%$.

VUS in genetic screening tests

A major argument against using genetic testing for screening, has been the issue of VUS. VUS are particularly common the more genes are included in a test. They are also more common in understudied populations and for more recently investigated genes. The justified concern is that if VUS are reported, this often leads to inappropriate overtreatment. The solution is 
not to report VUS in the screening setting. This is ethically justifiable because screening if not meant to identify $100 \%$ of individuals at risk. Indeed, non-return of VUS is already the policy in preconception carrier screening, in reporting secondary/incidental findings in genomic tests, and in return of results in clinical biobanks. Although this approach limits sensitivity (resulting in a certain proportion of false negatives), it has two critical benefits 1 ) it results in a high degree of specificity (minimizing false positives) 2) For BRCA screening, it may free policy makers to widen the scope of testing and improving the currently dismal ascertainment rates (148).

Acceptability of strategies for a population screening process (Table 1, principle 6),

Genetic counseling has long been considered a key component of the cancer risk assessment process(21).Its key components are education regarding the genetics of cancer, the likelihood of developing cancer, the likelihood of carrying a genetic susceptibility mutation, the benefits, risks and limitations of genetic susceptibility testing, and appropriate cancer screening and prevention strategies. The goal is to empower the patient to make informed decisions regarding screening, prevention and genetic testing by providing him or her with the necessary genetic, medical and psychosocial information. Attention to psychosocial issues is critical for effective genetic counseling $(22 ; 97)$.

As detailed above, existing guidelines (Table 2) recommend testing for BRCA mutations only with pretest and post-test in-person genetic counseling (GC). Pretest counseling is provided to collect familial information, evaluate the patient's cancer risk, generate a differential diagnosis and educate the patients (inheritance, penetrance), prepare the patient for all possible test results, and determine the appropriate genetic test (8). Post-test counseling is provided to explain test results, consider possible risk-reduction interventions risk based on 
risk-benefit analysis and patient preference and discuss informing family members and available resources. This labor intensive and time-consuming process is unique in clinical medicine. Historically it developed when Genetics was a niche field serving a more limited clientele tested for reproductive or predictive purposes whose implications were largely nontherapeutic - e.g decisions regarding prenatal testing, or predictive testing for untreatable conditions like Huntington's disease. Genetic counseling has been shown to be accompanied by high satisfaction and to enhance genetic knowledge. In the context of Cancer Genetics, genetic counseling has been shown to reduce breast cancer worry, anxiety, and depression, to improve the response to cancer risk management strategies such as screening, chemoprevention or preventive surgery, and to reduce long-term distress (reviewed by(31; 135) (78)

Compared to the rapid changes in genetic and genomic laboratory testing, the genetic counseling aspects of the testing process have been slow to evolve. However, there is a clear need for change in order to provide both for an ever-growing need as well as to a different patient profile. Importantly, if genomics is to be used for Precision Prevention, testing will increasingly include individuals with low apriori risk, for whom the full pretest discussion will most likely prove to be less relevant $(98 ; 99)$.

Our aim was to evaluate the pre-test process with a view towards a process that would be feasible at the large scale of population screening. To this end we first examined studies which examined alternative modalities compared to traditional, in-person GC (IP-GC), and that also included un-affected participants (vs. studies which included only participants affected with breast/ovarian cancer). We assessed studies published in the past decade (since 2009) which are representative of the current landscape of genomic testing and of greater public 
awareness. Based on these selection criteria, threealternative models could be evaluated: Telephone counseling, telegenic counseling and group counseling. These studies are summarized in Table 3.

Telephone vs. IP-GC: Five studies by two groups reported randomization of participants to receive telephone vs. IP-GC $(32 ; 87 ; 88 ; 144 ; 167)$. In these studies, satisfaction and knowledge after telephone counseling was non-inferior to IP-GC(144; 167) Non-inferiority was also observed for the vast majority of the measured psychological outcomes at two weeks post counseling and three months after the post-test $\mathrm{GC}(87 ; 167)$. Participants who received telephone GC found the counseling to be significantly more convenient, but they also perceived lower levels of support and emotional recognition(144). One-year post testing, telephone GC was non-inferior to traditional methods (87). However, despite the seeming similarity between the groups, up-take rates of genetic testing were $6-10 \%$ lower in the telephone counseling group vs. traditional IP-GC (Table 3).

Telegenetic vs. traditional IP-GC: Telegenetics is genetic counseling provided remotely by live videoconferencing, with visual and audio access(36). This counseling modality was studied in five papers by two groups $(195 ; 196))(29 ; 129)(172)$. Satisfaction in the telegenetic group was as high as in traditional IP-GC in all measured scales in all studies. Knowledge and psychological outcomes (anxiety, depression cancer-specific anxiety) improved equally in the telegenetic and GC-IP groups(172) (195). Genetic test uptake was examined in one study(29) and was similar after telegenetic and and IP- GC (54\% and 55\%, respectively). However, although vast majority of telegenetic GC participants reported they were comfortable with telegenetic counseing, a significant fraction of participants indicated they would have preferred IP-GC. This preference was reported in $4 / 5$ studies $(29 ; 172 ; 195 ; 196)$ 
Group vs. individual counseling: two studies measured the effect of group counseling vs. individual IP-GC (158; 164). Satisfaction was similar in both groups and $95 \%$ of group-GC participants said they would recommend it to others. However, $40 \%$ of participants who were offered group GC actively declined it and came for IP-GC (158). There were no appreciable improvements in knowledge (which was high a-priori) in either study group(164). Psychological outcomes were equal or non-inferior in both study groups except for significant reduction in avoidant thoughts (a subscale of the Impact of Events Scale (IES) which was demonstrated only in individual GC participants(164). Genetic testing uptake was lower in group GC vs. individual GC participants (47\% vs. $78 \%$ )(164). Another two studies, had an arm with a group component; both were studies of BRCA testing in low-risk AJs (Table 4). Manchanda et al. studied the advantage of a group DVD-based counselling (DVD-C) approach within the context of population testing (110). This model included a DVD presentation (Decision Aid) to small groups of volunteers (2-5) at a time, followed by individual IP-GC (postDVD) at the same appointment. DVD-C was not inferior to IP-GC with respect to increase in knowledge, risk perception, counselling satisfaction, and uptake of genetic testing. Compared to IP-GC, with DVD-C both counselling time and overall cost were significantly lower (Table 4). The second study, by Wiesman et al. offered founder variant testing to AJ. High risk participants received standard GC, and low risk participants were invited to a group GC session. In low risk participants survey responses indicated that $97 \%$ of low-risk participants expressed comfort with meeting in this setting, and virtually no one felt intimidated or pressured by the group (189).

To summarize, in unaffected individuals telephone, telegenetic and group counseling modalities are largely non-inferior to traditional GC. Using Decision Aids can make counselling more time and cost efficient. Telephone and telegenetic GC afford convenience, availability 
and accessibility, particularly for geographically distant patients, but may not improve waiting time or reduce manpower time. Taken together, all three modalities likely represent an incremental, rather than paradigmatic change in GC provision.

Two other models for a pre-test process that could be relevant to unaffected patients are the "Mainstreaming" and Direct Genetic Testing. The "Mainstreaming" genetic testing model engages non-geneticist clinicians to order genetic testing, typically with support from genetic clinicians(121). In this model, patients are referred to GC only post-testing, and only when a positive or inconclusive result are obtained. "Mainstreaming" has been studied and implemented largely in the Oncology setting, particularly for Oncologists' direct referral of ovarian cancer patients for genetic testing. Studies of "mainstreaming" in ovarian cancer patients found that referral rates and uptake were very high $(89 \%-100 \%)(60 ; 149 ; 173)$, compared to much lower rates (15-31\%) achieved through traditional GC (48). Patient waiting times were significantly reduced(60;149), and satisfaction was high( $38 ; 60 ; 149)$. In this scheme, all carriers are supposed to be referred for GC by a geneticist, and the actual referral rates observed were $100 \%(60)$ to $78 \%(149)$. In principle, the "mainstreaming" model could be adapted to unaffected individuals, and the family physician, gynecologist or breast surgeon could offer genetic testing during surveillance or routine appointments. However, the "mainstreaming" model is highly dependent on non-geneticist health-care providers and has not been easily transferable to other settings. For example, breast surgeons, as opposed to Oncologists, reported that they feel a lack of expertise in providing genetic counseling and support for patients regarding testing decisions, as well as concern about the time consuming process (70). The possibility of offering genetic services during routine provision of primary care has also been evaluated (130). Primary-care providers reported multiple barriers, chiefly insufficient knowledge and skills to counsel patients about genetic risk and to manage them. 
Similar concerns, including concerns about the ethical, social and legal implications were raised specifically regarding provision of Cancer Genetics care(71). Some studies showed increase in providers' knowledge and confidence after an educational Intervention (190) or by using suitable electronic tools(166). However the implementation of this approach requires re-training in order to achieve the necessary expertise or capacity to provide genetics services in non-Genetics settings. Mainstreaming would also shift part of the burden from genetic counselors to other clinical providers, and logistical issues, especially time allotment would need to be resolved.

Direct genetic testing models: In direct genetic testing, testing is performed without pre-test GC. This can be performed within a medical framework offering clinical support, or through direct to consumer commercial testing, outside the medical setting. In the medical setting, direct genetic testing shifts the balance to the post-test stage, so that the main counseling interaction, including risk assessment and recommendations, is already informed by the test results.

Direct genetic testing in a clinical setting: Few studies have compared outcomes of after direct GT to to pre-test GC. Only two studies included unaffected participants. The ABOUT study in the USA (14), was a retrospective study of individuals who had BRCA testing in community settings performed through Aetna (a commercial health insurer). Investigators compared knowledge, understanding and satisfaction between patients who did (73.2\%) or did not (38.6\%) receive pre-test GC. All measures were greater in individuals who received pre-test GC provided by a genetics clinician. Women who received pre-test GC reported significantly greater knowledge about $B R C A$, expressed greater understanding and greater satisfaction. Pal et al. studied the uptake of cancer risk management strategies among 438 women BRCA carriers from the Inherited Cancer Registry (ICARE) database (140) They showed that uptake 
rates of risk-reduction surgeries were similar among those whose tests were ordered by Genetics professional or by other health care providers (Oncologists, Surgeons and others) but MRI rates were significantly higher when pre-test GC session and the BRCA test was provided and ordered by a genetics professional(140).

In two large direct testing studies performed in unaffected AJ, the pre-test process included only written information materials.(98; 99; 126; 128)(Table 4). In both studies, genetic counselor support was available pre-testing, and post-testing all carriers and high risk noncarriers communicated with a genetic counselor post testing. Satisfaction with GT, in both studies, was high in both carriers and non-carriers, and there were high rates of recommending the same process for others. Despite this, among carriers, $55.6 \%(127)$, and $21 \%(98)$ indicated that in retrospect they would have preferred to have a pre-test IP-GC session. Distress was low among non-carriers, and in the short-term was significantly higher among carriers. Long term, distress level decreased, and there was very high compliance with screening recommendations and to RRSO (95\% in women age >35) (126).

Direct-to-consumer genetic testing (DTC-GT): DTC-GT has been available from the early 2000s, allowing consumers to access their own genetic information without involvement of a clinician and with no GC (11). These tests are generally performed using mailed-in saliva kits and are relatively inexpensive. This simplified process circumvents testing barriers described above, and provides greater autonomy $(157 ; 182)$. However it also lacks the clinical support necessary to follow up on medical information that can be revealed by DTC-GT. DTC-GT originally focused on SNP (single nucleotide polymorphism)-based risk assessment for complex diseases such as type 2 diabetes and osteoporosis, but in 2018, the U.S. Food and Drug Administration (FDA) authorized the 23andMe company to provide a Personal Genome Service Genetic Health Risk (GHR) Report for BRCA1/BRCA2 (Selected Variants) (61). This 
report provides results on the three AJ BRCA1/BRCA2 founder variants to all tested individuals, regardless of their ancestry.

For DTC-GT in general, SNP-based risk assessment results have not been associated with increased test-related or general distress and anxiety (27). There are conflicting reports on whether findings of increased disease risk lead to changes in health behaviors such as diet or exercise ((66), and reviewed by Stewart (174). Most tested individuals do not share their results with medical professionals: survey studies found that $10.4 \%$ and $1 \%$ of individuals shared results with a genetic counselor, while $26.5 \%$ and $39 \%$ shared results with a another health care physician/provider $(23 ; 82)$. However, none of these studies included results of carrier status for highly penetrant genes. 23andMe performed a study on their own return of AJ BRCA variant DTC testing(53). Among 25 newly diagnosed carriers, 11 were women, and of those $3(16 \%)$ experienced moderate anxiety, but none had severe anxiety. Regarding preventative actions, RRM was performed by one and planned by 3, RRSO was performed by 3 and planned by four (after completion of childbearing). $81 \%$ of women carriers shared information with at least one health care provider (53). It is important to recognize that beyond the specific BRCA AJ variants approved for testing, there have been significant concerns regarding the analytical validity of non-medical grade DTC-GT (176), with false positive rates as high as $40 \%$. Obviously this is a critical issue and results obtained from nonmedical grade DTC-GT must be re-confirmed by diagnostic testing. Another emerging model in this landscape is the hybrid model of direct testing, where a clinician orders a medical grade test and communicates the result, but the test itself is sent and often paid-for by the patient(146). The hybrid model thus combines the features of medically based "Mainstreaming" while still offering convenience and choice. Concerns include issues of cost/insurance coverage, continuity of care and ensuring selection of the correct test. To 
summarize, direct testing can be performed in a full medical setting that only omits pretest counseling, in a hybrid fashion, or completely at the hands of the consumer. While these processes are already being utilized, there are no randomized or comparative studies that have evaluated their performance vs. traditional GC or compared to one another(146).

Optimally the goal would be to strike a balance that provides individual autonomy, but through choices that are informed. A process that would maintain a clinical framework ensuring that the appropriate, medical grade tests are performed and that patients have access to professional interpretation of their results and provision of appropriate care. We suggest the term "Direct to Patient" as embodying these goals.

For population screening of $A J$ for the founder $B R C A 1 / B R C A 2$ variants, we believe that the streamlined process has been shown by us and by others (Table 4) to strike such a balance. In the pretest stage this includes written information /education materials and a standardized self-administered family history questionnaires. Post testing, only at-risk individuals, i.e. carriers and those non-carriers who have significant family history are recalled for in-person genetic counseling. We recognize that different health systems may need context specific adaptable pathways resulting in different models for implementation, while maintaining the principles of population screening.

\section{G. Cost effectiveness of BRCA1/BRCA2 population screening (Table 1, principle 9)}

Advances in high throughput sequencing technologies and bioinformatics along with falling costs of BRCA testing has made population testing feasible. A health economic evaluation is essential to evaluate the costs and consequences of different health strategies/interventions. This helps health policy decision making related to cost efficient resource allocation across interventions. For interventions to be sustainable they need to be cost-effective and 
affordable. A few studies have evaluated the cost-effectiveness of population-based BRCA testing in the Jewish population. An initial cost-utility analysis compared population based BRCA-testing in Ashkenazi Jewish (AJ) women aged 35-55 years with 'no testing' and showed that population-testing was cost-effective.(165) However this study was limited in its interpretation as it used the comparator of 'no testing' instead of true standard of care which is clinical-criteria or family-history $(\mathrm{FH})$ based testing. Additionally health outcomes only included ovarian cancer, while breast cancer related management and outcomes were excluded from the analysis. Manchanda et al published a cost-effectiveness analysis comparing Population based BRCA founder mutation testing with clinical-criteria/FH-based testing from the GCaPPS trial (ISRCTN73338115), and showed that population-based testing was cost saving for the UK health system, with a discounted incremental cost-effectiveness ratio (ICER) of -2079/QALY and $94 \%$ simulations being cost-effective on probabilistic sensitivity analysis (PSA).(112) Population-based testing was found to lower ovarian and breast cancer incidence by $0.34 \%$ and $0.62 \%$, leading to 276 fewer ovarian cancer and 508 fewer breast cancer cases. Overall, reduction in treatment costs led to a discounted costsaving of $£ 3.7$ million. These findings were based on a $\sim 2.5 \% B R C A$ prevalence found in individuals with four AJ grandparents. However, $25 \%$ of UK(64) and $44 \%$ of USA(145) Jewish marriages are with non-Jews. Hence, some Jewish individuals may have just one, two or three AJ grandparents and therefore the prevalence of $B R C A 1 / B R C A 2$ mutations is lower in these groups. An updated cost-effectiveness analysis comparing population-based BRCA-testing with clinical-criteria/FH-based testing in individuals with varying levels of Jewish ancestry reconfirmed that population-based $B R C A$ testing remained cost-effective in all these scenarios for both US and UK health systems.(116) Population testing remained cost-saving in AJ women with 2-4 AJ grandparents. The ICERs ranged from -2960f/QALY to -1254f/QALY 
for UK and -19587\$/QALY to -12013\$/QALY for USA. For individuals with one AJ grandparent population testing was cost-effective for UK (ICER= $€ 863 / \mathrm{QALY})$ and cost-saving for US analysis ICER $=-2542 / Q A L Y)$.(116) PSA showed that $\geq 95 \%$ of simulations are cost-effective for population-testing at the $\mathrm{f20,000/QALY} \mathrm{NICE} \mathrm{willingness-to-pay} \mathrm{(WTP)} \mathrm{and} \$ 100,000 / Q A L Y$ USA WTP thresholds. This suggests, compared to current clinical policy of clinical-criteria/FHbased clinical-testing, population testing in four, three, two and one AJ grandparent(s) is highly cost-effective. BRCA mutation prevalence is lower in Sephardi Jews $(0.5 \%-1 \%)(17 ; 18)$ compared to Ashkenazim.(115) One cost-utility analysis compared lifetime costs and effects of population based BRCA1 founder mutation testing (Figure-1) with clinical-criteria/FH testing to population testing in all Sephardi Jewish women using a Markov model. They reported that population testing was cost-effective with an ICER of $f 67.04 / Q A L Y$ for UK and \$308.42/QALY for US populations respectively.(143) 100\% simulations were cost-effective for population testing on PSA. Overall there appears to be good data showing that population based $B R C A$ founder mutation testing is cost-effective in the Jewish population and it may be cost-saving in most scenarios.

While there are robust data supporting population-based BRCA testing in the Jewish population, corresponding data in the non-Jewish general population are much more limited, but beginning to emerge. In a recent study Manchanda et al compared population based testing for moderate and high-penetrance ovarian and breast cancer gene mutations (BRCA1, BRCA2, RAD51C, RAD51D, BRIP1, PALB2) with standard clinical-criteria or FH-based $B R C A 1 / B R C A 2$ testing as well as with clinical-criteria or FH-based panel (BRCA1, BRCA2, RAD51C, RAD51D, BRIP1, PALB2) testing in general population British and American women over 30 years.(117) They showed that unselected Population-based panel testing for BRCA1, 
BRCA2, RAD51C, RAD51D, BRIP1 and PALB2 mutations was extremely cost-effective compared to either of the above clinical-criteria/FH-based restricted testing strategies, with ICER $=£ 21,599.96 / Q A L Y$ or $\$ 54,769.78 / Q A L Y$ for the UK and USA respectively. These are well below the willingness to pay (WTP) thresholds of the UK ( $f 30,000 / \mathrm{QALY})$ and the USA (\$100,000/QALY). PSA showed that population-based (BRCA1, BRCA2, RAD51C, RAD51D, BRIP1, PALB2) panel-testing was cost-effective in $83.7 \%$ and $92.7 \%$ simulations for UK and US health systems respectively.(117) In comparison, clinical-criteria/FH-based panel testing was cost-effective only in $16.2 \%$ and $5.8 \%$ simulations and clinical-criteria/FH-based $B R C A 1 / B R C A 2$ testing was cost-effective for only $0.1 \%$ and $1.5 \%$ simulations in UK and US women respectively. A new BRCA1, BRCA2, RAD51C, RAD51D, BRIP1, PALB2 populationtesting strategy could potentially prevent thousands more breast and ovarian cancer cases over and above current policy. It amounted to preventing $1.86 \% / 1.91 \%$ breast cancers and $3.2 \% / 4.88 \%$ ovarian cancers in UK/USA women respectively, which translated to $657 / 655$ ovarian cancer cases and 2420/2386 breast cancer cases prevented per million respectively. The overall population impact was estimated to be an additional 17,505 ovarian cancer cases and 64,493 breast cancer cases prevented in UK women, and additional 65,221 ovarian cancer and 237,610 breast cancer cases prevented in US women.(117) Zhang et al showed that population testing for BRCA1, BRCA2, MLH1, MSH2, cystic fibrosis (CF), spinal muscular atrophy (SMA), and fragile X syndrome (FXS), in all Australian individuals aged 18-25 years in Australia was extremely cost-effective with an ICER= AUD\$7286/DALY.(93; 193) Such a strategy was found to potentially reduce variant-attributable cancers by $28.8 \%$, cancer deaths by $31.2 \%$, and CF/SMA/FXS cases by cases by $24.8 \%$ compared to the current clinical strategy.(193). 


\section{H. Health system considerations - available facilities and sustainability of population}

screening. (Table 1, principles 3,10). As detailed above, population screening includes multiple components. In most developed countries the facilities for outreach, laboratory testing, genetic counseling and the necessary medical surveillance and prevention facilities already exist. Creating population screening programs will nevertheless require varying degrees of reorganization or restructuring of certain services, especially if they are to be continuous and sustainable. These adaptations will be specific to each health system, depending on its general structure. Some countries with more centralized health systems may choose to create formal screening programs, while other countries may opt for "open access" testing within the medical system.

\section{Conclusions}

There is a consensus that BRCA1/BRCA2 deleterious variants are clinically actionable, and that it is medically worthwhile for carriers to be aware of their genetic status. Preventive strategies in carriers, particularly RRSO, have been shown to be life-saving. Yet current schemes identify less than $20 \%$ of all carriers (Geisinger), and probably less than $10 \%$ of unaffected carriers(76). Overall $90-97 \%$ estimated at risk carriers in the population remain unidentified. (ref) manchanda $2018 \mathrm{~J}$ Med genet

In this review we examine population screening of Ashkenazi Jews for BRCA1/BRCA2 deleterious variants as a paradigm for a Precision Prevention strategy. We assessed such screening in the light of established principles of disease screening. We believe it is clear that testing for the founder variants fulfills these criteria. In non-Ashkenazi populations, emerging data on the frequency of $B R C A 1 / B R C A 2$ deleterious variants suggests that full sequencing of these genes may similarly fulfill screening criteria. Population screening in both AJ and non- 
$\mathrm{AJ}$, or at the very least open access to testing, may begin to address the major gaps in carrier identification.

Fulfilling the promise of Cancer Genetics to Precision Prevention requires transforming the testing process from a limited activity subject to multiple barriers, to a public health endeavor. We believe it is incumbent on the medical system to enable a "Direct to Patient" model, one that both facilitates responsible testing and offers a framework for appropriate care. A shift in scale also entails a shift in perspective. A case in point is using the existence of VUS or testing for low-penetrance or very rare genes as arguments against sequencing-based screening. This is a situation of "perfect" being the enemy of "very good". If clear medical actionability is the paramount consideration, it is certainly possible not to report VUS and not to test moderate/low penetrance genes in the screening setting. These issues are important topics for further research, but they should not keep us from doing what is already possible.

Acknowledgements: E.L.L is supported by the Breast Cancer Research Foundation (NY). R.M. is supported by The Eve Appeal and NHS Innovation Accelerator Fellowship for research into population testing. 


\section{Literature Cited}

1. American Cancer Society (ACS). Cancer Facts \& Figures 2019 ACS website.

https://www.cancer.org/content/dam/cancer-org/research/cancer-facts-andstatistics/annual-cancer-facts-and-figures/2019/cancer-facts-and-figures-2019.pdf

2. American Cancer Society (ACS). Global CancerFacts \& Figures 4th Edition (2018). https://www.cancer.org/content/dam/cancer-org/research/cancer-facts-andstatistics/global-cancer-facts-and-figures/global-cancer-facts-and-figures-4th-edition.pdf

3. ExAC Exome Aggregation Consortium. https://gnomad.broadinstitute.org/

4. Help Me Understand Genetics page: National Library of Medicine (US). Genetics Home Reference. What is Precision Medicine? https://ghr-nlm-nihgov.offcampus.lib.washington.edu/primer/precisionmedicine/definition

5. Kaurah P, Huntsman DG. Hereditary Diffuse Gastric Cancer. 2002 Nov 4 [Updated 2018 Mar 22]. In: Adam MP, Ardinger HH, Pagon RA, et al., editors. GeneReviews ${ }^{\circledR}$ [Internet]. Seattle (WA): University of Washington, Seattle; 1993-2019. . https://www.ncbi.nlm.nih.gov/books/NBK1139/

6. McGarrity TJ, Amos Cl, Baker MJ. Peutz-Jeghers Syndrome. 2001 Feb 23 [Updated 2016 Jul 14]. In: Adam MP, Ardinger HH, Pagon RA, et al., editors. GeneReviews ${ }^{\circledR}$ [Internet]. Seattle (WA): University of Washington, Seattle; 1993-2019.

https://www.ncbi.nlm.nih.gov/books/NBK1266/

7. National Heart, Lung, and Blood Institute: NHLBI exome sequencing project (ESP): Exome variant server. . http://evs.gs.washington.edu/EVS/

8. NCCN guildeines: Genetic/familial high-risk assessment, breast, ovarian and pancreatic. Version 1.2020.

9. NICE-Familial breast cancer: classification, care and managing breast cancer and related risks in people with a family history of breast cancer Clinical guideline [CG164] Published date: June 2013 Last updated: November 2019.

https://www.nice.org.uk/guidance/cg164/chapter/Recommendations\#terms-used-in-thisguideline

10. Schneider K, Zelley K, Nichols KE, Garber J. Li-Fraumeni Syndrome. 1999 Jan 19 [Updated 2019 Nov 21]. In: Adam MP, Ardinger HH, Pagon RA, et al., editors. GeneReviews ${ }^{\circledR}$ [Internet]. Seattle (WA): University of Washington, Seattle; 1993-2019. .

https://www.ncbi.nIm.nih.gov/books/NBK1311/

11. Allyse MA, Robinson DH, Ferber MJ, Sharp RR. 2018. Direct-to-Consumer Testing 2.0: Emerging Models of Direct-to-Consumer Genetic Testing. Mayo Clin Proc 93:113-20

12. Alsop K, Fereday S, Meldrum C, deFazio A, Emmanuel C, et al. 2012. BRCA mutation frequency and patterns of treatment response in BRCA mutation-positive women with ovarian cancer: a report from the Australian Ovarian Cancer Study Group. Journal of clinical oncology : official journal of the American Society of Clinical Oncology 30:2654-63

13. Anderson K, Jacobson JS, Heitjan DF, Zivin JG, Hershman D, et al. 2006. Cost-effectiveness of preventive strategies for women with a BRCA1 or a BRCA2 mutation. Annals of internal medicine 144:397-406

14. Armstrong J, Toscano M, Kotchko N, Friedman S, Schwartz MD, et al. 2015. Utilization and Outcomes of BRCA Genetic Testing and Counseling in a National Commercially Insured Population: The ABOUT Study. JAMA Oncol 1:1251-60

15. Armstrong K, Schwartz JS, Randall T, Rubin SC, Weber B. 2004. Hormone replacement therapy and life expectancy after prophylactic oophorectomy in women with BRCA1/2 mutations: a decision analysis. Journal of clinical oncology : official journal of the American Society of Clinical Oncology 22:1045-54

16. Armstrong N, Ryder S, Forbes C, Ross J, Quek RG. 2019. A systematic review of the international prevalence of BRCA mutation in breast cancer. Clin Epidemiol 11:543-61 
17. Bar-Sade RB, Kruglikova A, Modan B, Gak E, Hirsh-Yechezkel G, et al. 1998. The 185delAG BRCA1 mutation originated before the dispersion of Jews in the diaspora and is not limited to Ashkenazim. Human molecular genetics 7:801-5

18. Bar-Sade RB, Theodor L, Gak E, Kruglikova A, Hirsch-Yechezkel G, et al. 1997. Could the 185delAG BRCA1 mutation be an ancient Jewish mutation? European journal of human genetics : EJHG 5:413-6

19. Bashford MT, Kohlman W, Everett J, Parrott A, Pollin TI. 2019. Addendum: A practice guideline from the American College of Medical Genetics and Genomics and the National Society of Genetic Counselors: referral indications for cancer predisposition assessment. Genetics in medicine : official journal of the American College of Medical Genetics 21:2844

20. Beitsch PD, Whitworth PW, Hughes K, Patel R, Rosen B, et al. 2019. Underdiagnosis of Hereditary Breast Cancer: Are Genetic Testing Guidelines a Tool or an Obstacle? Journal of clinical oncology : official journal of the American Society of Clinical Oncology 37:453-60

21. Berliner JL, Fay AM. 2007. Risk assessment and genetic counseling for hereditary breast and ovarian cancer: recommendations of the National Society of Genetic Counselors. J Genet Couns 16:241-60

22. Bernhardt BA, Biesecker BB, Mastromarino CL. 2000. Goals, benefits, and outcomes of genetic counseling: client and genetic counselor assessment. American journal of medical genetics 94:189-97

23. Bloss CS, Schork NJ, Topol EJ. 2011. Effect of direct-to-consumer genomewide profiling to assess disease risk. The New England journal of medicine 364:524-34

24. Blyuss O, Burnell M, Ryan A, Gentry-Maharaj A, Marino IP, et al. 2018. Comparison of Longitudinal CA125 Algorithms as a First-Line Screen for Ovarian Cancer in the General Population. Clinical cancer research : an official journal of the American Association for Cancer Research 24:4726-33

25. Brandberg Y, Sandelin K, Erikson S, Jurell G, Liljegren A, et al. 2008. Psychological reactions, quality of life, and body image after bilateral prophylactic mastectomy in women at high risk for breast cancer: a prospective 1-year follow-up study. Journal of clinical oncology : official journal of the American Society of Clinical Oncology 26:3943-9

26. Bray F, Ferlay J, Soerjomataram I, Siegel RL, Torre LA, Jemal A. 2018. Global cancer statistics 2018: GLOBOCAN estimates of incidence and mortality worldwide for 36 cancers in 185 countries. CA Cancer J Clin 68:394-424

27. Broady KM, Ormond KE, Topol EJ, Schork NJ, Bloss CS. 2018. Predictors of adverse psychological experiences surrounding genome-wide profiling for disease risk. Journal of community genetics 9:217-25

28. Bubien V, Bonnet F, Brouste V, Hoppe S, Barouk-Simonet E, et al. 2013. High cumulative risks of cancer in patients with PTEN hamartoma tumour syndrome. Journal of medical genetics 50:255-63

29. Buchanan AH, Datta SK, Skinner CS, Hollowell GP, Beresford HF, et al. 2015. Randomized Trial of Telegenetics vs. In-Person Cancer Genetic Counseling: Cost, Patient Satisfaction and Attendance. J Genet Couns 24:961-70

30. Buchanan AH, Manickam K, Meyer MN, Wagner JK, Hallquist MLG, et al. 2018. Early cancer diagnoses through BRCA1/2 screening of unselected adult biobank participants. Genetics in medicine : official journal of the American College of Medical Genetics 20:554-8

31. Buchanan AH, Rahm AK, Williams JL. 2016. Alternate Service Delivery Models in Cancer Genetic Counseling: A Mini-Review. Front Oncol 6:120

32. Butrick M, Kelly S, Peshkin BN, Luta G, Nusbaum R, et al. 2015. Disparities in uptake of BRCA1/2 genetic testing in a randomized trial of telephone counseling. Genetics in medicine : official journal of the American College of Medical Genetics 17:467-75

33. Casey MJ, Synder C, Bewtra C, Narod SA, Watson P, Lynch HT. 2005. Intra-abdominal carcinomatosis after prophylactic oophorectomy in women of hereditary breast ovarian 
cancer syndrome kindreds associated with BRCA1 and BRCA2 mutations. Gynecologic oncology 97:457-67

34. Chen S, Parmigiani G. 2007. Meta-analysis of BRCA1 and BRCA2 penetrance. Journal of Clinical Oncology 25:1329-33

35. Claus EB, Risch N, Thompson WD. 1991. Genetic analysis of breast cancer in the cancer and steroid hormone study. American journal of human genetics 48:232-42

36. Cohen SA, Gustafson SL, Marvin ML, Riley BD, Uhlmann WR, et al. 2012. Report from the National Society of Genetic Counselors service delivery model task force: a proposal to define models, components, and modes of referral. J Genet Couns 21:645-51

37. Collins FS, Varmus H. 2015. A New Initiative on Precision Medicine. New England Journal of Medicine 372:793-5

38. Colombo N, Huang G, Scambia G, Chalas E, Pignata S, et al. 2018. Evaluation of a Streamlined Oncologist-Led BRCA Mutation Testing and Counseling Model for Patients With Ovarian Cancer. Journal of clinical oncology : official journal of the American Society of Clinical Oncology 36:1300-7

39. Couch FJ, Shimelis H, Hu C, Hart SN, Polley EC, et al. 2017. Associations Between Cancer Predisposition Testing Panel Genes and Breast Cancer. JAMA Oncol 3:1190-6

40. Cuzick J. 2017. Preventive therapy for cancer. Lancet Oncol 18:e472-e82

41. Del Corral GA, Wes AM, Fischer JP, Serletti JM, Wu LC. 2015. Outcomes and Cost Analysis in High-Risk Patients Undergoing Simultaneous Free Flap Breast Reconstruction and Gynecologic Procedures. Ann Plast Surg 75:534-8

42. Domchek SM, Friebel TM, Singer CF, Evans DG, Lynch HT, et al. 2010. Association of riskreducing surgery in BRCA1 or BRCA2 mutation carriers with cancer risk and mortality. JAMA : the journal of the American Medical Association 304:967-75

43. Domchek SM, Friebel TM, Singer CF, Evans DG, Lynch HT, et al. 2010. Association of riskreducing surgery in BRCA1 or BRCA2 mutation carriers with cancer risk and mortality. JAMA 304:967-75

44. Drescher CW, Shah C, Thorpe J, O'Briant K, Anderson GL, et al. 2013. Longitudinal screening algorithm that incorporates change over time in CA125 levels identifies ovarian cancer earlier than a single-threshold rule. Journal of clinical oncology : official journal of the American Society of Clinical Oncology 31:387-92

45. Easton DF, Pharoah PD, Antoniou AC, Tischkowitz M, Tavtigian SV, et al. 2015. Gene-panel sequencing and the prediction of breast-cancer risk. The New England journal of medicine 372:2243-57

46. Ellison G, Wallace A, Kohlmann A, Patton S. 2017. A comparative study of germline BRCA1 and BRCA2 mutation screening methods in use in 20 European clinical diagnostic laboratories. British journal of cancer 117:710-6

47. Fakkert IE, Abma EM, Westrik IG, Lefrandt JD, Wolffenbuttel BH, et al. 2015. Bone mineral density and fractures after risk-reducing salpingo-oophorectomy in women at increased risk for breast and ovarian cancer. European journal of cancer (Oxford, England : 1990) 51:400-8

48. Febbraro T, Robison K, Wilbur JS, Laprise J, Bregar A, et al. 2015. Adherence patterns to National Comprehensive Cancer Network (NCCN) guidelines for referral to cancer genetic professionals. Gynecologic oncology 138:109-14

49. Finch A, Beiner M, Lubinski J, Lynch HT, Moller P, et al. 2006. Salpingo-oophorectomy and the risk of ovarian, fallopian tube, and peritoneal cancers in women with a BRCA1 or BRCA2 Mutation. JAMA : the journal of the American Medical Association 296:185-92

50. Finch A, Shaw P, Rosen B, Murphy J, Narod SA, Colgan TJ. 2006. Clinical and pathologic findings of prophylactic salpingo-oophorectomies in 159 BRCA1 and BRCA2 carriers. Gynecologic oncology 100:58-64 
51. Finch AP, Lubinski J, Moller P, Singer CF, Karlan B, et al. 2014. Impact of oophorectomy on cancer incidence and mortality in women with a BRCA1 or BRCA2 mutation. Journal of clinical oncology : official journal of the American Society of Clinical Oncology 32:1547-53

52. Forbes C, Fayter D, de Kock S, Quek RG. 2019. A systematic review of international guidelines and recommendations for the genetic screening, diagnosis, genetic counseling, and treatment of BRCA-mutated breast cancer. Cancer Manag Res 11:2321-37

53. Francke U, Dijamco C, Kiefer AK, Eriksson N, Moiseff B, et al. 2013. Dealing with the unexpected: consumer responses to direct-access BRCA mutation testing. PeerJ 1:e8

54. Frank TS, Deffenbaugh AM, Reid JE, Hulick M, Ward BE, et al. 2002. Clinical characteristics of individuals with germline mutations in BRCA1 and BRCA2: analysis of 10,000 individuals. Journal of clinical oncology : official journal of the American Society of Clinical Oncology 20:1480-90

55. Friebel TM, Domchek SM, Rebbeck TR. 2014. Modifiers of cancer risk in BRCA1 and BRCA2 mutation carriers: systematic review and meta-analysis. Journal of the National Cancer Institute 106:dju091

56. Gaba F, Piek J, Menon U, Manchanda R. 2019. Risk-reducing early salpingectomy and delayed oophorectomy as a two-staged alternative for primary prevention of ovarian cancer in women at increased risk: a commentary. BJOG 126:831-9

57. Gabai-Kapara E, Lahad A, Kaufman B, Friedman E, Segev S, et al. 2014. Population-based screening for breast and ovarian cancer risk due to BRCA1 and BRCA2. Proceedings of the National Academy of Sciences of the United States of America 111:14205-10

58. Garcia C, Wendt J, Lyon L, Jones J, Littell RD, et al. 2014. Risk management options elected by women after testing positive for a BRCA mutation. Gynecologic oncology 132:428-33

59. Gayther SA, Mangion J, Russell P, Seal S, Barfoot R, et al. 1997. Variation of risks of breast and ovarian cancer associated with different germline mutations of the BRCA2 gene. Nature genetics 15:103-5

60. George A, Riddell D, Seal S, Talukdar S, Mahamdallie S, et al. 2016. Implementing rapid, robust, cost-effective, patient-centred, routine genetic testing in ovarian cancer patients. Scientific reports 6:29506

61. Gill J, Obley AJ, Prasad V. 2018. Direct-to-Consumer Genetic Testing: The Implications of the US FDA's First Marketing Authorization for BRCA Mutation Testing. JAMA : the journal of the American Medical Association 319:2377-8

62. Gordhandas S, Norquist BM, Pennington KP, Yung RL, Laya MB, Swisher EM. 2019. Hormone replacement therapy after risk reducing salpingo-oophorectomy in patients with BRCA1 or BRCA2 mutations; a systematic review of risks and benefits. Gynecologic oncology 153:192200

63. Gorski B, Jakubowska A, Huzarski T, Byrski T, Gronwald J, et al. 2004. A high proportion of founder BRCA1 mutations in Polish breast cancer families. International journal of cancer 110:683-6

64. Graham D, Schmool M, Waterman S. 2007. Jews in Britain: a snapshot from the 2001 Census, Institute for Jewish Policy Research, London

65. Grann VR, Patel PR, Jacobson JS, Warner E, Heitjan DF, et al. 2011. Comparative effectiveness of screening and prevention strategies among BRCA1/2-affected mutation carriers. Breast cancer research and treatment 125:837-47

66. Gray SW, Gollust SE, Carere DA, Chen CA, Cronin A, et al. 2017. Personal Genomic Testing for Cancer Risk: Results From the Impact of Personal Genomics Study. Journal of Clinical Oncology 35:636-44

67. Green RC, Berg JS, Grody WW, Kalia SS, Korf BR, et al. 2013. ACMG recommendations for reporting of incidental findings in clinical exome and genome sequencing. Genetics in Medicine 15:565-74 
68. Green RF, Ari M, Kolor K, Dotson WD, Bowen S, et al. 2019. Evaluating the role of public health in implementation of genomics-related recommendations: a case study of hereditary cancers using the CDC Science Impact Framework. Genetics in medicine : official journal of the American College of Medical Genetics 21:28-37

69. Greene MH, Piedmonte M, Alberts D, Gail M, Hensley M, et al. 2008. A prospective study of risk-reducing salpingo-oophorectomy and longitudinal CA-125 screening among women at increased genetic risk of ovarian cancer: design and baseline characteristics: a gynecologic oncology group study. Cancer epidemiology, biomarkers \& prevention : a publication of the American Association for Cancer Research, cosponsored by the American Society of Preventive Oncology 17:594-604

70. Hallowell N, Wright S, Stirling D, Gourley C, Young O, Porteous M. 2019. Moving into the mainstream: healthcare professionals' views of implementing treatment focussed genetic testing in breast cancer care. Familial cancer 18:293-301

71. Hamilton JG, Abdiwahab E, Edwards HM, Fang ML, Jdayani A, Breslau ES. 2017. Primary care providers' cancer genetic testing-related knowledge, attitudes, and communication behaviors: A systematic review and research agenda. J Gen Intern Med 32:315-24

72. Heemskerk-Gerritsen BA, Seynaeve C, van Asperen CJ, Ausems MG, Collee JM, et al. 2015. Breast cancer risk after salpingo-oophorectomy in healthy BRCA1/2 mutation carriers: revisiting the evidence for risk reduction. Journal of the National Cancer Institute 107

73. Heemskerk-Gerritsen BAM, Jager A, Koppert LB, Obdeijn AI, Collee M, et al. 2019. Survival after bilateral risk-reducing mastectomy in healthy BRCA1 and BRCA2 mutation carriers. Breast cancer research and treatment

74. Hirsh-Yechezkel G, Chetrit A, Lubin F, Friedman E, Peretz T, et al. 2003. Population attributes affecting the prevalence of BRCA mutation carriers in epithelial ovarian cancer cases in israel. Gynecologic oncology 89:494-8

75. Hopper JL, Southey MC, Dite GS, Jolley DJ, Giles GG, et al. 1999. Population-based estimate of the average age-specific cumulative risk of breast cancer for a defined set of proteintruncating mutations in BRCA1 and BRCA2. Australian Breast Cancer Family Study. Cancer epidemiology, biomarkers \& prevention : a publication of the American Association for Cancer Research, cosponsored by the American Society of Preventive Oncology 8:741-7

76. Hughes KS. 2017. Genetic Testing: What Problem Are We Trying to Solve? Journal of clinical oncology : official journal of the American Society of Clinical Oncology 35:3789-91

77. Isern AE, Tengrup I, Loman N, Olsson H, Ringberg A. 2008. Aesthetic outcome, patient satisfaction, and health-related quality of life in women at high risk undergoing prophylactic mastectomy and immediate breast reconstruction. Journal of plastic, reconstructive \& aesthetic surgery : JPRAS 61:1177-87

78. Jacobs C, Patch C, Michie S. 2019. Communication about genetic testing with breast and ovarian cancer patients: a scoping review. European journal of human genetics : EJHG 27:511-24

79. Kalia SS, Adelman K, Bale SJ, Chung WK, Eng C, et al. 2017. Recommendations for reporting of secondary findings in clinical exome and genome sequencing, 2016 update (ACMG SF v2.0): a policy statement of the American College of Medical Genetics and Genomics. Genetics in medicine : official journal of the American College of Medical Genetics 19:249-55

80. Kauff ND, Domchek SM, Friebel TM, Robson ME, Lee J, et al. 2008. Risk-reducing salpingooophorectomy for the prevention of BRCA1- and BRCA2-associated breast and gynecologic cancer: a multicenter, prospective study. Journal of clinical oncology : official journal of the American Society of Clinical Oncology 26:1331-7

81. Kauff ND, Satagopan JM, Robson ME, Scheuer L, Hensley M, et al. 2002. Risk-reducing salpingo-oophorectomy in women with a BRCA1 or BRCA2 mutation. The New England journal of medicine 346:1609-15 
82. Kaufman DJ, Bollinger JM, Dvoskin RL, Scott JA. 2012. Risky business: risk perception and the use of medical services among customers of DTC personal genetic testing. J Genet Couns 21:413-22

83. Kaurah P, MacMillan A, Boyd N, Senz J, De Luca A, et al. 2007. Founder and recurrent CDH1 mutations in families with hereditary diffuse gastric cancer. JAMA : the journal of the American Medical Association 297:2360-72

84. Khoury MJ, McCabe LL, McCabe ER. 2003. Population screening in the age of genomic medicine. The New England journal of medicine 348:50-8

85. King MC, Levy-Lahad E, Lahad A. 2014. Population-based screening for BRCA1 and BRCA2: 2014 Lasker Award. JAMA : the journal of the American Medical Association 312:1091-2

86. King MC, Marks JH, Mandell JB. 2003. Breast and ovarian cancer risks due to inherited mutations in BRCA1 and BRCA2. Science (New York, N.Y.) 302:643-6

87. Kinney AY, Butler KM, Schwartz MD, Mandelblatt JS, Boucher KM, et al. 2014. Expanding access to BRCA1/2 genetic counseling with telephone delivery: a cluster randomized trial. Journal of the National Cancer Institute 106

88. Kinney AY, Steffen LE, Brumbach BH, Kohlmann W, Du R, et al. 2016. Randomized Noninferiority Trial of Telephone Delivery of BRCA1/2 Genetic Counseling Compared With In-Person Counseling: 1-Year Follow-Up. Journal of clinical oncology : official journal of the American Society of Clinical Oncology 34:2914-24

89. Kuchenbaecker KB, Hopper JL, Barnes DR, Phillips KA, Mooij TM, et al. 2017. Risks of Breast, Ovarian, and Contralateral Breast Cancer for BRCA1 and BRCA2 Mutation Carriers. JAMA : the journal of the American Medical Association 317:2402-16

90. Kuchenbaecker KB, McGuffog L, Barrowdale D, Lee A, Soucy P, et al. 2017. Evaluation of Polygenic Risk Scores for Breast and Ovarian Cancer Risk Prediction in BRCA1 and BRCA2 Mutation Carriers. Journal of the National Cancer Institute 109

91. Kurian AW, Hughes E, Handorf EA, Gutin A, Allen B, et al. 2017. Breast and Ovarian Cancer Penetrance Estimates Derived From Germline Multiple-Gene Sequencing Results in Women. JCO Precision Oncology:1-12

92. Kurian AW, Ward KC, Howlader N, Deapen D, Hamilton AS, et al. 2019. Genetic Testing and Results in a Population-Based Cohort of Breast Cancer Patients and Ovarian Cancer Patients. Journal of clinical oncology : official journal of the American Society of Clinical Oncology 37:1305-15

93. Lacaze P, Tiller J, Bao Y, Riaz M, Winship I, Zhang L. 2019. Response to Veenstra et al. Genetics in medicine : official journal of the American College of Medical Genetics 21:2842-3

94. Lancaster JM, Powell CB, Chen LM, Richardson DL. 2015. Society of Gynecologic Oncology statement on risk assessment for inherited gynecologic cancer predispositions. Gynecologic oncology 136:3-7

95. Landrum MJ, Lee JM, Riley GR, Jang W, Rubinstein WS, et al. 2014. ClinVar: public archive of relationships among sequence variation and human phenotype. Nucleic acids research 42:D980-5

96. Lee K, Seifert BA, Shimelis H, Ghosh R, Crowley SB, et al. 2019. Clinical validity assessment of genes frequently tested on hereditary breast and ovarian cancer susceptibility sequencing panels. Genetics in medicine : official journal of the American College of Medical Genetics 21:1497-506

97. Lerman C, Lustbader E, Rimer B, Daly M, Miller S, et al. 1995. Effects of individualized breast cancer risk counseling: a randomized trial. Journal of the National Cancer Institute 87:286-92

98. Lieberman S, Lahad A, Tomer A, Cohen C, Levy-Lahad E, Raz A. 2017. Population screening for BRCA1/BRCA2 mutations: lessons from qualitative analysis of the screening experience. Genetics in medicine : official journal of the American College of Medical Genetics 19:628-34

99. Lieberman S, Tomer A, Ben-Chetrit A, Olsha O, Strano S, et al. 2017. Population screening for BRCA1/BRCA2 founder mutations in Ashkenazi Jews: proactive recruitment compared with 
self-referral. Genetics in medicine : official journal of the American College of Medical Genetics 19:754-62

100. Lilyquist J, LaDuca H, Polley E, Davis BT, Shimelis H, et al. 2017. Frequency of mutations in a large series of clinically ascertained ovarian cancer cases tested on multi-gene panels compared to reference controls. Gynecologic oncology 147:375-80

101. Lincoln SE, Kobayashi Y, Anderson MJ, Yang S, Desmond AJ, et al. 2015. A Systematic Comparison of Traditional and Multigene Panel Testing for Hereditary Breast and Ovarian Cancer Genes in More Than 1000 Patients. The Journal of molecular diagnostics : JMD 17:533-44

102. Lord CJ, Ashworth A. 2017. PARP inhibitors: Synthetic lethality in the clinic. Science (New York, N.Y.) 355:1152-8

103. Madalinska JB, Hollenstein J, Bleiker E, van Beurden M, Valdimarsdottir HB, et al. 2005. Quality-of-life effects of prophylactic salpingo-oophorectomy versus gynecologic screening among women at increased risk of hereditary ovarian cancer. Journal of clinical oncology : official journal of the American Society of Clinical Oncology 23:6890-8

104. Madalinska JB, van Beurden M, Bleiker EM, Valdimarsdottir HB, Hollenstein J, et al. 2006. The impact of hormone replacement therapy on menopausal symptoms in younger high-risk women after prophylactic salpingo-oophorectomy. Journal of clinical oncology : official journal of the American Society of Clinical Oncology 24:3576-82

105. Mai PL, Best AF, Peters JA, DeCastro RM, Khincha PP, et al. 2016. Risks of first and subsequent cancers among TP53 mutation carriers in the National Cancer Institute LiFraumeni syndrome cohort. Cancer 122:3673-81

106. Manchanda R, Abdelraheim A, Johnson M, Rosenthal AN, Benjamin E, et al. 2011. Outcome of risk-reducing salpingo-oophorectomy in BRCA carriers and women of unknown mutation status. BJOG : an international journal of obstetrics and gynaecology 118:814-24

107. Manchanda R, Blyuss O, Gaba F, Gordeev VS, Jacobs C, et al. 2018. Current detection rates and time-to-detection of all identifiable BRCA carriers in the Greater London population. Journal of medical genetics 55:538-45

108. Manchanda R, Burnell M, Abdelraheim A, Johnson M, Sharma A, et al. 2012. Factors influencing uptake and timing of risk reducing salpingo-oophorectomy in women at risk of familial ovarian cancer: a competing risk time to event analysis. BJOG 119:527-36

109. Manchanda R, Burnell M, Gaba F, Desai R, Wardle J, et al. 2019. Randomised trial of population-based BRCA testing in Ashkenazi Jews: long-term outcomes. Bjog

110. Manchanda R, Burnell M, Loggenberg K, Desai R, Wardle J, et al. 2016. Cluster-randomised non-inferiority trial comparing DVD-assisted and traditional genetic counselling in systematic population testing for BRCA1/2 mutations. Journal of medical genetics 53:472-80

111. Manchanda R, Legood R, Antoniou AC, Gordeev VS, Menon U. 2016. Specifying the ovarian cancer risk threshold of 'premenopausal risk-reducing salpingo-oophorectomy' for ovarian cancer prevention: a cost-effectiveness analysis. Journal of medical genetics 53:591-9

112. Manchanda R, Legood R, Burnell M, McGuire A, Raikou M, et al. 2015. Cost-effectiveness of population screening for BRCA mutations in Ashkenazi jewish women compared with family history-based testing. Journal of the National Cancer Institute 107:380

113. Manchanda R, Legood R, Pearce L, Menon U. 2015. Defining the risk threshold for risk reducing salpingo-oophorectomy for ovarian cancer prevention in low risk postmenopausal women. Gynecologic oncology 139:487-94

114. Manchanda R, Loggenberg K, Sanderson S, Burnell M, Wardle J, et al. 2015. Population testing for cancer predisposing BRCA1/BRCA2 mutations in the ashkenazi-jewish community: A randomized controlled trial. Journal of the National Cancer Institute 107

115. Manchanda R, Loggenberg K, Sanderson S, Burnell M, Wardle J, et al. 2015. Population testing for cancer predisposing BRCA1/BRCA2 mutations in the Ashkenazi-Jewish community: a randomized controlled trial. Journal of the National Cancer Institute 107:379 
116. Manchanda R, Patel S, Antoniou AC, Levy-Lahad E, Turnbull C, et al. 2017. Cost-effectiveness of population based BRCA testing with varying Ashkenazi Jewish ancestry. Am J Obstet Gynecol 217:578 e1- e12

117. Manchanda R, Patel S, Gordeev VS, Antoniou AC, Smith S, et al. 2018. Cost-effectiveness of Population-Based BRCA1, BRCA2, RAD51C, RAD51D, BRIP1, PALB2 Mutation Testing in Unselected General Population Women. Journal of the National Cancer Institute 110:714-25

118. Manickam K, Buchanan AH, Schwartz MLB, Hallquist MLG, Williams JL, et al. 2018. Exome Sequencing-Based Screening for BRCA1/2 Expected Pathogenic Variants Among Adult Biobank Participants. JAMA Netw Open 1:e182140

119. Mavaddat N, Peock S, Frost D, Ellis S, Platte R, et al. 2013. Cancer risks for BRCA1 and BRCA2 mutation carriers: Results from prospective analysis of EMBRACE. Journal of the National Cancer Institute 105:812-22

120. Maxwell KN, Domchek SM, Nathanson KL, Robson ME. 2016. Population Frequency of Germline BRCA1/2 Mutations. Journal of clinical oncology : official journal of the American Society of Clinical Oncology 34:4183-5

121. McCuaig JM, Armel SR, Care M, Volenik A, Kim RH, Metcalfe KA. 2018. Next-Generation Service Delivery: A Scoping Review of Patient Outcomes Associated with Alternative Models of Genetic Counseling and Genetic Testing for Hereditary Cancer. Cancers (Basel) 10

122. Medeiros F, Muto MG, Lee Y, Elvin JA, Callahan MJ, et al. 2006. The tubal fimbria is a preferred site for early adenocarcinoma in women with familial ovarian cancer syndrome. Am J Surg Pathol 30:230-6

123. Menon U, Ryan A, Kalsi J, Gentry-Maharaj A, Dawnay A, et al. 2015. Risk Algorithm Using Serial Biomarker Measurements Doubles the Number of Screen-Detected Cancers Compared With a Single-Threshold Rule in the United Kingdom Collaborative Trial of Ovarian Cancer Screening. Journal of clinical oncology : official journal of the American Society of Clinical Oncology

124. Metcalfe K, Eisen A, Senter L, Armel S, Bordeleau L, et al. 2019. International trends in the uptake of cancer risk reduction strategies in women with a BRCA1 or BRCA2 mutation. British journal of cancer

125. Metcalfe KA, Birenbaum-Carmeli D, Lubinski J, Gronwald J, Lynch H, et al. 2008. International variation in rates of uptake of preventive options in BRCA1 and BRCA2 mutation carriers. International journal of cancer 122:2017-22

126. Metcalfe KA, Mian N, Enmore M, Poll A, Llacuachaqui M, et al. 2012. Long-term follow-up of Jewish women with a BRCA1 and BRCA2 mutation who underwent population genetic screening. Breast cancer research and treatment 133:735-40

127. Metcalfe KA, Poll A, Llacuachaqui M, Nanda S, Tulman A, et al. 2010. Patient satisfaction and cancer-related distress among unselected Jewish women undergoing genetic testing for BRCA1 and BRCA2. Clinical genetics 78:411-7

128. Metcalfe KA, Poll A, Royer R, Llacuachaqui M, Tulman A, et al. 2010. Screening for founder mutations in BRCA1 and BRCA2 in unselected Jewish women. Journal of clinical oncology: official journal of the American Society of Clinical Oncology 28:387-91

129. Mette LA, Saldivar AM, Poullard NE, Torres IC, Seth SG, et al. 2016. Reaching high-risk underserved individuals for cancer genetic counseling by video-teleconferencing. $J$ Community Support Oncol 14:162-8

130. Mikat-Stevens NA, Larson IA, Tarini BA. 2015. Primary-care providers' perceived barriers to integration of genetics services: a systematic review of the literature. Genetics in medicine : official journal of the American College of Medical Genetics 17:169-76

131. Moller P, Hagen Al, Apold J, Maehle L, Clark N, et al. 2007. Genetic epidemiology of BRCA mutations--family history detects less than $50 \%$ of the mutation carriers. European journal of cancer (Oxford, England : 1990) 43:1713-7 
132. Moslehi R, Chu W, Karlan B, Fishman D, Risch H, et al. 2000. BRCA1 and BRCA2 mutation analysis of 208 Ashkenazi Jewish women with ovarian cancer. American journal of human genetics 66:1259-72

133. Nelson HD, Fu R, Goddard K, Mitchell JP, Okinaka-Hu L, et al. 2013. In Risk Assessment, Genetic Counseling, and Genetic Testing for BRCA-Related Cancer: Systematic Review to Update the U.S. Preventive Services Task Force Recommendation. Rockville (MD). Number of.

134. Nelson HD, Fu R, Zakher B, Pappas M, McDonagh M. 2019. Medication Use for the Risk Reduction of Primary Breast Cancer in Women: Updated Evidence Report and Systematic Review for the US Preventive Services Task Force. JAMA : the journal of the American Medical Association 322:868-86

135. Nelson HD, Pappas M, Cantor A, Haney E, Holmes R. 2019. Risk Assessment, Genetic Counseling, and Genetic Testing for BRCA-Related Cancer in Women: Updated Evidence Report and Systematic Review for the US Preventive Services Task Force. JAMA : the journal of the American Medical Association 322:666-85

136. NICE. 2017. Familial breast cancer: classification, care and managing breast cancer and related risks in people with a family history of breast cancer. $p$.

https://www.nice.org.uk/guidance/cg164. London, UK: National Institute for Health and Care Excellence

137. Norquist BM, Brady MF, Harrell MI, Walsh T, Lee MK, et al. 2018. Mutations in Homologous Recombination Genes and Outcomes in Ovarian Carcinoma Patients in GOG 218: An NRG Oncology/Gynecologic Oncology Group Study. Clinical cancer research : an official journal of the American Association for Cancer Research 24:777-83

138. Norquist BM, Harrell MI, Brady MF, Walsh T, Lee MK, et al. 2016. Inherited Mutations in Women With Ovarian Carcinoma. JAMA Oncol 2:482-90

139. Owens DK, Davidson KW, Krist AH, Barry MJ, Cabana M, et al. 2019. Risk Assessment, Genetic Counseling, and Genetic Testing for BRCA-Related Cancer: US Preventive Services Task Force Recommendation Statement. JAMA : the journal of the American Medical Association 322:652-65

140. Pal T, Lee JH, Besharat A, Thompson Z, Monteiro AN, et al. 2014. Modes of delivery of genetic testing services and the uptake of cancer risk management strategies in BRCA1 and BRCA2 carriers. Clinical genetics 85:49-53

141. Parker WH, Feskanich D, Broder MS, Chang E, Shoupe D, et al. 2013. Long-term mortality associated with oophorectomy compared with ovarian conservation in the nurses' health study. Obstetrics and gynecology 121:709-16

142. Parmigiani G, Chen S, Iversen Jr ES, Friebel TM, Finkelstein DM, et al. 2007. Validity of models for predicting BRCA1 and BRCA2 mutations. Annals of internal medicine 147:441-50

143. Patel S, Legood R, Evans DG, Turnbull C, Antoniou AC, et al. 2018. Cost effectiveness of population based BRCA1 founder mutation testing in Sephardi Jewish women. Am J Obstet Gynecol 218:431 e1- e12

144. Peshkin BN, Kelly S, Nusbaum RH, Similuk M, DeMarco TA, et al. 2016. Patient Perceptions of Telephone vs. In-Person BRCA1/BRCA2 Genetic Counseling. J Genet Couns 25:472-82

145. Pew Research Center. 2013. A Portrait of Jewish Americans. In Findings from a Pew Research Center Survey of U.S. Jews. Washington DC, USA: Pew Research Center

146. Phillips KA, Trosman JR, Douglas MP. 2019. Emergence of Hybrid Models of Genetic Testing Beyond Direct-to-Consumer or Traditional Labs. JAMA : the journal of the American Medical Association 321:2403-4

147. Powell CB. 2014. Risk reducing salpingo-oophorectomy for BRCA mutation carriers: twenty years later. Gynecologic oncology 132:261-3

148. Prince AE, Berg JS, Evans JP, Jonas DE, Henderson G. 2015. Genomic screening of the general adult population: key concepts for assessing net benefit with systematic evidence reviews. Genetics in medicine : official journal of the American College of Medical Genetics 17:441-3 
149. Rahman B, Lanceley A, Kristeleit RS, Ledermann JA, Lockley M, et al. 2019. Mainstreamed genetic testing for women with ovarian cancer: first-year experience. Journal of medical genetics 56:195-8

150. Rebbeck TR. 2014. Precision prevention of cancer. Cancer epidemiology, biomarkers \& prevention : a publication of the American Association for Cancer Research, cosponsored by the American Society of Preventive Oncology 23:2713-5

151. Rebbeck TR, Burns-White K, Chan AT, Emmons K, Freedman M, et al. 2018. Precision Prevention and Early Detection of Cancer: Fundamental Principles. Cancer Discov 8:803-11

152. Rebbeck TR, Friebel T, Lynch HT, Neuhausen SL, van 't Veer L, et al. 2004. Bilateral prophylactic mastectomy reduces breast cancer risk in BRCA1 and BRCA2 mutation carriers: the PROSE Study Group. Journal of clinical oncology : official journal of the American Society of Clinical Oncology 22:1055-62

153. Rebbeck TR, Kauff ND, Domchek SM. 2009. Meta-analysis of risk reduction estimates associated with risk-reducing salpingo-oophorectomy in BRCA1 or BRCA2 mutation carriers. Journal of the National Cancer Institute 101:80-7

154. Rebbeck TR, Lynch HT, Neuhausen SL, Narod SA, Van't Veer L, et al. 2002. Prophylactic oophorectomy in carriers of BRCA1 or BRCA2 mutations. The New England journal of medicine 346:1616-22

155. Rebbeck TR, Mitra N, Wan F, Sinilnikova OM, Healey S, et al. 2015. Association of type and location of BRCA1 and BRCA2 mutations with risk of breast and ovarian cancer. JAMA : the journal of the American Medical Association 313:1347-61

156. Rebelatto TF, Falavigna M, Pozzari M, Spada F, Cella CA, et al. 2019. Should platinum-based chemotherapy be preferred for germline BReast CAncer genes (BRCA) 1 and 2-mutated pancreatic ductal adenocarcinoma (PDAC) patients? A systematic review and meta-analysis. Cancer Treat Rev 80:101895

157. Reid RJ, McBride CM, Alford SH, Price C, Baxevanis AD, et al. 2012. Association between health-service use and multiplex genetic testing. Genetics in medicine : official journal of the American College of Medical Genetics 14:852-9

158. Ridge Y, Panabaker K, McCullum M, Portigal-Todd C, Scott J, McGillivray B. 2009. Evaluation of group genetic counseling for hereditary breast and ovarian cancer. J Genet Couns 18:87100

159. Roa BB, Boyd AA, Volcik K, Richards CS. 1996. Ashkenazi Jewish population frequencies for common mutations in BRCA1 and BRCA2. Nature genetics 14:185-7

160. Rocca WA, Bower JH, Maraganore DM, Ahlskog JE, Grossardt BR, et al. 2007. Increased risk of cognitive impairment or dementia in women who underwent oophorectomy before menopause. Neurology 69:1074-83

161. Rosenthal AN, Fraser L, Manchanda R, Badman P, Philpott S, et al. 2013. Results of annual screening in phase I of the United Kingdom familial ovarian cancer screening study highlight the need for strict adherence to screening schedule. Journal of clinical oncology : official journal of the American Society of Clinical Oncology 31:49-57

162. Rosenthal AN, Fraser LSM, Philpott S, Manchanda R, Burnell M, et al. 2017. Evidence of Stage Shift in Women Diagnosed With Ovarian Cancer During Phase II of the United Kingdom Familial Ovarian Cancer Screening Study. Journal of clinical oncology : official journal of the American Society of Clinical Oncology 35:1411-20

163. Rosenthal E, Moyes K, Arnell C, Evans B, Wenstrup RJ. 2015. Incidence of BRCA1 and BRCA2 non-founder mutations in patients of Ashkenazi Jewish ancestry. Breast cancer research and treatment 149:223-7

164. Rothwell E, Kohlmann W, Jasperson K, Gammon A, Wong B, Kinney A. 2012. Patient outcomes associated with group and individual genetic counseling formats. Familial cancer 11:97-106 
165. Rubinstein WS, Jiang H, Dellefave L, Rademaker AW. 2009. Cost-effectiveness of populationbased BRCA1/2 testing and ovarian cancer prevention for Ashkenazi Jews: a call for dialogue. Genetics in medicine : official journal of the American College of Medical Genetics 11:629-39

166. Scheuner MT, Hamilton AB, Peredo J, Sale TJ, Austin C, et al. 2014. A cancer genetics toolkit improves access to genetic services through documentation and use of the family history by primary-care clinicians. Genetics in medicine : official journal of the American College of Medical Genetics 16:60-9

167. Schwartz MD, Valdimarsdottir HB, Peshkin BN, Mandelblatt J, Nusbaum R, et al. 2014. Randomized noninferiority trial of telephone versus in-person genetic counseling for hereditary breast and ovarian cancer. Journal of clinical oncology : official journal of the American Society of Clinical Oncology 32:618-26

168. Schwartz MLB, McCormick CZ, Lazzeri AL, Lindbuchler DM, Hallquist MLG, et al. 2018. A Model for Genome-First Care: Returning Secondary Genomic Findings to Participants and Their Healthcare Providers in a Large Research Cohort. American journal of human genetics 103:328-37

169. Shirts BH, Casadei S, Jacobson AL, Lee MK, Gulsuner S, et al. 2016. Improving performance of multigene panels for genomic analysis of cancer predisposition. Genetics in medicine : official journal of the American College of Medical Genetics 18:974-81

170. Shuster LT, Gostout BS, Grossardt BR, Rocca WA. 2008. Prophylactic oophorectomy in premenopausal women and long-term health. Menopause Int 14:111-6

171. Skates SJ, Greene MH, Buys SS, Mai PL, Brown P, et al. 2017. Early Detection of Ovarian Cancer using the Risk of Ovarian Cancer Algorithm with Frequent CA125 Testing in Women at Increased Familial Risk - Combined Results from Two Screening Trials. Clinical cancer research : an official journal of the American Association for Cancer Research

172. Solomons NM, Lamb AE, Lucas FL, McDonald EF, Miesfeldt S. 2018. Examination of the Patient-Focused Impact of Cancer Telegenetics Among a Rural Population: Comparison with Traditional In-Person Services. Telemed J E Health 24:130-8

173. Stearnes G, Nichols CB, Schofield L, O'Sullivan S, Pachter N, Cohen PA. 2019. Uptake of testing for germline BRCA mutations in patients with non-mucinous epithelial ovarian cancers in Western Australia: a comparison of different genetic counseling methods. International journal of gynecological cancer : official journal of the International Gynecological Cancer Society 29:1038-42

174. Stewart KFJ, Wesselius A, Schreurs MAC, Schols A, Zeegers MP. 2018. Behavioural changes, sharing behaviour and psychological responses after receiving direct-to-consumer genetic test results: a systematic review and meta-analysis. Journal of community genetics 9:1-18

175. Tan MH, Mester JL, Ngeow J, Rybicki LA, Orloff MS, Eng C. 2012. Lifetime cancer risks in individuals with germline PTEN mutations. Clinical cancer research : an official journal of the American Association for Cancer Research 18:400-7

176. Tandy-Connor S, Guiltinan J, Krempely K, LaDuca H, Reineke P, et al. 2018. False-positive results released by direct-to-consumer genetic tests highlight the importance of clinical confirmation testing for appropriate patient care. Genetics in medicine : official journal of the American College of Medical Genetics 20:1515-21

177. Teerlink CC, Albright FS, Lins L, Cannon-Albright LA. 2012. A comprehensive survey of cancer risks in extended families. Genetics in Medicine 14:107-14

178. Thavaneswaran S, Rath E, Tucker K, Joshua AM, Hess D, et al. 2019. Therapeutic implications of germline genetic findings in cancer. Nat Rev Clin Oncol 16:386-96

179. Thompson ER, Rowley SM, Li N, McInerny S, Devereux L, et al. 2016. Panel Testing for Familial Breast Cancer: Calibrating the Tension Between Research and Clinical Care. Journal of clinical oncology : official journal of the American Society of Clinical Oncology 34:1455-9 
180. Tung N, Lin NU, Kidd J, Allen BA, Singh N, et al. 2016. Frequency of Germline Mutations in 25 Cancer Susceptibility Genes in a Sequential Series of Patients With Breast Cancer. Journal of clinical oncology : official journal of the American Society of Clinical Oncology 34:1460-8

181. Uglanitsa N, Oszurek O, Uglanitsa K, Savonievich E, Lubinski J, et al. 2010. The contribution of founder mutations in BRCA1 to breast cancer in Belarus. Clinical genetics 78:377-80

182. Vayena E. 2015. Direct-to-consumer genomics on the scales of autonomy. J Med Ethics 41:310-4

183. Venkitaraman AR. 2019. How do mutations affecting the breast cancer genes BRCA1 and BRCA2 cause cancer susceptibility? DNA Repair (Amst) 81:102668

184. Vogel VG, Costantino JP, Wickerham DL, Cronin WM, Cecchini RS, et al. 2010. Update of the National Surgical Adjuvant Breast and Bowel Project Study of Tamoxifen and Raloxifene (STAR) P-2 Trial: Preventing breast cancer. Cancer Prev Res (Phila) 3:696-706

185. Walsh T, Casadei S, Lee MK, Pennil CC, Nord AS, et al. 2011. Mutations in 12 genes for inherited ovarian, fallopian tube, and peritoneal carcinoma identified by massively parallel sequencing. Proceedings of the National Academy of Sciences of the United States of America 108:18032-7

186. Walsh T, Mandell JB, Norquist BM, Casadei S, Gulsuner S, et al. 2017. Genetic Predisposition to Breast Cancer Due to Mutations Other Than BRCA1 and BRCA2 Founder Alleles Among Ashkenazi Jewish Women. JAMA Oncol 3:1647-53

187. Wasteson E, Sandelin K, Brandberg Y, Wickman M, Arver B. 2011. High satisfaction rate ten years after bilateral prophylactic mastectomy - a longitudinal study. European journal of cancer care 20:508-13

188. Weitzel JN, Lagos VI, Cullinane CA, Gambol PJ, Culver JO, et al. 2007. Limited family structure and BRCA gene mutation status in single cases of breast cancer. JAMA : the journal of the American Medical Association 297:2587-95

189. Wiesman C, Rose E, Grant A, Zimilover A, Klugman S, Schreiber-Agus N. 2017. Experiences from a pilot program bringing BRCA1/2 genetic screening to theUS Ashkenazi Jewish population. Genetics in medicine : official journal of the American College of Medical Genetics 19:529-36

190. Wilkes MS, Day FC, Fancher TL, McDermott H, Lehman E, et al. 2017. Increasing confidence and changing behaviors in primary care providers engaged in genetic counselling. BMC Med Educ 17:163

191. Wilson J, Jungner G. 1968. Principles and practice of screening for disease. . Geneva, Switzerland: World Health Organization

192. Xicola RM, Li S, Rodriguez N, Reinecke P, Karam R, et al. 2019. Clinical features and cancer risk in families with pathogenic $\mathrm{CDH} 1$ variants irrespective of clinical criteria. Journal of medical genetics 56:838-43

193. Zhang L, Bao Y, Riaz M, Tiller J, Liew D, et al. 2019. Population genomic screening of all young adults in a health-care system: a cost-effectiveness analysis. Genetics in medicine : official journal of the American College of Medical Genetics 21:1958-68

194. Zhang S, Royer R, Li S, McLaughlin JR, Rosen B, et al. 2011. Frequencies of BRCA1 and BRCA2 mutations among 1,342 unselected patients with invasive ovarian cancer. Gynecologic oncology 121:353-7

195. Zilliacus EM, Meiser B, Lobb EA, Kelly PJ, Barlow-Stewart K, et al. 2011. Are videoconferenced consultations as effective as face-to-face consultations for hereditary breast and ovarian cancer genetic counseling? Genetics in medicine : official journal of the American College of Medical Genetics 13:933-41

196. Zilliacus EM, Meiser B, Lobb EA, Kirk J, Warwick L, Tucker K. 2010. Women's experience of telehealth cancer genetic counseling. J Genet Couns 19:463-72 